\title{
A MODEL OF MORAL-HAZARD CREDIT CYCLES
}

\author{
by Roger B. Myerson \\ March 2010, revised September 2012 \\ http://home.uchicago.edu/ rmyerson/research/bankers.pdf
}

Abstract: This paper considers a simple model of credit cycles driven by moral hazard in financial intermediation. Financial agents or bankers must earn moral-hazard rents, but the cost of these rents can be efficiently spread over an agent's entire career, by promising large late-career rewards if the agent has a consistently successful record. Dynamic interactions among different generations of financial agents can create credit cycles with repeated booms and recessions. In recessions, a scarcity of trusted financial intermediaries limits investment and reduces employment. Under such conditions, taxing workers to subsidize bankers may increase employment enough to make the workers better off.

\section{Introduction}

This paper analyzes a simple model to show how boom-bust credit cycles can be sustained in economies with moral hazard in financial intermediation. Problems of moral hazard in banks and other financial institutions were evident at many stages of the recent financial crisis, but the role of moral hazard has been less clear in traditional macroeconomic theory. As Freixas and Rochet (1997) have noted, modern microeconomic models of banking depend on advances in information economics and agency theory which were not available when the traditional Keynesian and monetarist theories were first developed. So now, as economists confront the need for deeper insights into the forces that can drive macroeconomic instability, we should consider new models that can apply the microeconomic theory of banking to the macroeconomic theory of business cycles.

In particular, we should recognize that moral hazard in financial intermediation has a fundamental role at the heart of any capitalist economy. A successful economy requires industrial concentrations of capital that are vastly larger than any typical individual's wealth, and the mass of small investors must rely on specialists to do the work of identifying good investment opportunities. So the flow of capital to industrial investments must depend on a relatively small group of financial intermediaries, in banks and other financial institutions, who decide how to invest great sums of other people's wealth. But individuals who hold such financial power may be tempted to abuse it for their own personal profit. To solve this problem of financial moral hazard, a successful capitalist economy needs a system of incentives for bankers and other financial intermediaries that can deter such abuse of power. 
Since Becker and Stigler (1974) and Shapiro and Stiglitz (1984), it has been well understood in agency theory that dynamic moral-hazard problems with limited liability are efficiently solved by promising large end-of-career rewards for agents who maintain good performance records. So an efficient solution to moral hazard in banking must involve long-term promises of large late-career rewards for individual bankers. Such back-loading of moral-hazard agency rents requires that bankers must anticipate some kind of long-term relationship with investors. So agency considerations can compel investors to accept limits on the liquidity of their investments, even in a world where physical investments may be short-term in nature. As the prospect of long-term career rewards is essential for motivating bankers to identify appropriate investments, investors' ability to trust their bankers must depend on expectations about long-term future profits in banking. At any point in time, the value of mid-career bankers' positions depends on the recent history of the economy and so becomes a state variable that can affect the level of current investment. When trusted bankers become scarce, aggregate investment must decline. Thus, long-term solutions to financial moral hazard can create dynamic forces that drive aggregate economic fluctuations. This basic insight underlies all the analysis in this paper.

The model in this paper is designed to probe these effects of financial moral hazard on dynamic economic equilibria in the simplest possible context. The analysis here shows how, even in an environment that is stationary and nonstochastic, boom-and-bust credit cycles can be driven purely by concerns of financial moral hazard. In such cycles, when investment is weak, a bailout or stimulus that uses poor workers' taxes to subsidize rich bankers might actually make the workers better off.

To highlight the effects of financial moral hazard, the model here simplifies away most other dynamic economic factors. We consider a simple economic environment with one commodity and labor, with no money or other long-term assets that could become illiquid investments, and so questions of long-term asset pricing are absent from the analysis here. Bankers' contracts with investors are the only long-term assets that have nontrivial price dynamics in this model. The analytical focus here is on how expectations of future profits in banking can affect the cost of financial intermediation for current investment.

These simplifying assumptions make this paper complementary to other important contributions to this literature on agency effects in macroeconomic dynamics. The model here is closely related to the classic model of Bernanke and Gertler (1989) and to the moral-hazard 
model of Suarez and Sussman (1997), which also consider simple dynamic economies without long-term assets. In the Bernanke-Gertler and Suarez-Sussman models, the dynamic state variable is the aggregate wealth of entrepreneurs, who are subject to moral hazard in the second period of their two-period careers, but our model here shifts the focus to moral hazard of financial intermediaries whose careers can span any given number of periods. As in other standard models of financial intermediation (Diamond, 1984; Holmstrom and Tirole, 1997; Philippon, 2008), the problem of moral hazard in financial intermediation can be derived here from a more basic problem of moral hazard in entrepreneurship, but financial intermediaries here are distinguished by their long-term relationships with investors.

Several other recent papers have also offered theoretical models to show how macroeconomic instability can be derived from incentive constraints in microeconomic transactions. Like this paper, Sussman and Suarez (1997, 2007), Li and Wang (2010), Gu and Wright (2011), Favara (2012), and Matsuyama (2012) analyze dynamic models in which macroeconomic fluctuations can be driven by moral hazard in one sector, with no exogenous shocks. Closely related models that involve adverse selection have been developed by Azariadis and Smith (1998), Reichlin and Siconolfi (2004), Martin (2008), and Figueroa and Leukhina (2010). Other important credit-cycle models of Kiyotaki and Moore (1997), He and Krishnamurthy (2008), and Brunnermeier and Sannikov (2009) have analyzed how the prices of long-term assets can dynamically depend on the aggregate wealth of agents who are subject to moral-hazard constraints, but the investors in these models cannot solve moral-hazard problems by using long-term career incentives in agency contracts.

This paper may be distinguished from the previous literature by our consideration of long-term incentive contracts over more than two periods. One new result that we get from long-term contracting in this model is that the rate of growth must be gradual but contractions can be steep (see condition [7] below). This fundamental asymmetry between bounded growth rates and unbounded contraction rates could not be derived in a two-period model.

The most important goal of our model is to show how basic standard assumptions about long-term moral-hazard contracting in financial intermediation imply the general possibility of macroeconomic fluctuations. The long-term contracts that we analyze here are quite standard in the literature on dynamic moral hazard (see for example Tirole, 2006, p. 184), and the formulation here has been particularly influenced by Biais et al. (2010).

We assume that investors can freely recruit any number of new young bankers every 
period. So at any point in time there will be different cohorts of bankers of different ages who will have accumulated contractual promises and assets in long-term relationships with their investors. The aggregate values of the contractual positions of these different cohorts of midcareer bankers will form the dynamic state of our economic model, which can change cyclically over time.

One might compare the relational assets of bankers of various ages to the accumulated investments in physical capital of various ages in a standard growth model. But there is a crucial difference between investments in physical capital and investments in long-term relationships with financial agents. The standard economic assumption about physical capital is that investors incur the cost of a unit of physical capital at the beginning of its life, and then the productive value of the capital investment depreciates over time. In contrast, the standard economic assumption about dynamic moral-hazard relationships is that the cost of moral-hazard rents is largely incurred by investors at the end of the agent's career, and so the value of the relationship actually increases over time, as end-of-career rewards draw closer, until the agent retires. This crucial distinction implies that moral-hazard rents of different cohorts of financial agents cannot be simply aggregated like investments in capital of different vintages. Thus, a simple one-sector model with long-term moral-hazard rents can generate complex dynamics that are fundamentally different from a simple one-sector model with long-term capital investment.

Section II considers a simple problem of optimal incentives for financial agents with moral hazard, to provide a microeconomic basis for our macro model. Then Section III develops our model of a dynamic economy and provides a general characterization of its equilibria and credit cycles. The rest of the paper applies or extends the framework from Section III. Section IV extends the analysis of aggregate demand for investment and employment in the model. Dynamic equilibria of an illustrative example are examined in Sections V and VIII, and the benefits of subsidies for financial stabilization or stimulus are analyzed in Sections VI and VII. Section IX considers the problem of liquidity for investors, and Section X introduces the question of extending the model with stochastic macroeconomic shocks. Conclusions are summarized in Section XI. Most proofs are gathered in the Appendix.

\section{A simple model of moral hazard in financial intermediation}

This section develops micro-agency foundations for our macro-dynamic model. At any period in this model, there may be many bankers or financial agents of different ages, each of 
whom can supervise one investment of any size within some wide range. We may assume that the minimal size for an investment is much larger than the typical individual could ever earn in a lifetime, which is why people need to pool their savings and delegate the supervision of their joint investment to a specialized financial agent. But the financial agent's control over a large investment of other people's savings can create moral-hazard problems.

Let us consider a simple standard moral-hazard problem in which an investment of size $\mathrm{h}$ at time $\mathrm{t}$ will return, at time $\mathrm{t}+1$, either $\pi_{\mathrm{t}+1} \mathrm{~h}$ if the investment succeeds or 0 if the investment fails. The probability of success will depend on whether the financial agent acts appropriately or wrongly in supervising the investment. The probability of success is $\alpha$ if the agent acts appropriately, but the probability of success is $\beta$ if the agent acts wrongly, where $\beta<\alpha$. This decrease in the probability of success would be the only publicly observable implication of the agent's wrongful behavior, but such wrongful supervision of this investment would also yield hidden private benefits worth $\gamma \mathrm{h}$ to the financial agent at time t. Let us suppose that all individuals are risk neutral and discount the future at rate $\rho$ per period. We will make assumptions sufficient to guarantee that, in equilibrium, it would never be worthwhile to make a wrongly supervised investment, even when the agent's $\gamma$ private benefit is taken into account:

$$
\gamma \mathrm{h}+\beta \pi_{\mathrm{t}+1} \mathrm{~h} /(1+\rho)<\mathrm{h} .
$$

To motivate the agent to supervise appropriately at time $t$, the agent must be promised a greater reward from success in the next period $t+1$ than from failure. Let $v$ denote the value to the agent of her promised reward next period if her supervised investment succeeds, and let w denote the value of the agent's reward at time $\mathrm{t}+1$ if the investment fails. Then the basic moralhazard incentive constraint requires that that the agent must expect at least as much from acting appropriately as from acting wrongly:

$$
[\alpha \mathrm{v}+(1-\alpha) \mathrm{w}] /(1+\rho) \geq \gamma \mathrm{h}+[\beta \mathrm{v}+(1-\beta) \mathrm{w}] /(1+\rho) .
$$

This implies $\mathrm{v}-\mathrm{w} \geq \mathrm{h}(1+\rho) \gamma /(\alpha-\beta)$, and so $\alpha \mathrm{v}+(1-\alpha) \mathrm{w} \geq \mathrm{w}+\mathrm{h} \alpha(1+\rho) \gamma /(\alpha-\beta)$.

We also assume limited liability, that the agent's rewards must be nonnegative: $\mathrm{w} \geq 0, \mathrm{v} \geq 0$. Let $\mathrm{M}=\alpha(1+\rho) \gamma /(\alpha-\beta)$, which can be interpreted as the expected moral-hazard rent for the agent next period, per unit of investment that the agent supervises this period. So the agent's expected reward at time $\mathrm{t}+1$ from supervising an investment of size $\mathrm{h}$ at time $\mathrm{t}$ must satisfy $\alpha v+(1-\alpha) w \geq h M$. From this inequality, we get the following result.

Fact 1 . For any given investment $\mathrm{h}>0$, the agent's expected reward $\alpha \mathrm{v}+(1-\alpha) \mathrm{w}$ at time 
$\mathrm{t}+1$ is minimized, over all feasible $(\mathrm{v}, \mathrm{w})$ satisfying incentive compatibility [2] and limited liability, by an incentive-compatible contract that promises rewards $\mathrm{v}=\mathrm{hM} / \alpha$ for success and $\mathrm{w}=0$ for failure. Under this plan, $\alpha \mathrm{v}+(1-\alpha) \mathrm{w}=\mathrm{hM}$.

Let $r_{t+1}=\alpha \pi_{t+1}-(1+\rho)$ denote the rate of expected surplus returns at time $t+1$, per unit invested at time t. (The "surplus" here is over the cost of invested funds, which would be $(1+\rho) h$ at time $\mathrm{t}+1$ if $\mathrm{h}$ was invested at time $\mathrm{t}$.) In our dynamic macro model, we will assume that the return rates $\pi_{t+1}$ and $r_{t+1}$ may depend on the time period because a rise in aggregate investment activity can increase the prices of inputs and decrease the prices of outputs for these investment projects. But for now, in our micro-foundations, we may simply take these expected return rates $\pi_{t+1}$ and $r_{t+1}$ as given for each period $t$. We assume that $r_{t+1} \geq 0$ for all $t$.

We are assuming that all investments are short-term one-period projects, but we allow that agents can have long-term careers. To be specific, let us assume that each financial agent lives $n+1$ periods, and so can supervise investments in $n$ periods. An agent could not supervise investment in her last period of life, because she could not then be motivated to appropriate behavior by promised rewards of success next period. But an agent whose life will span time periods $\{t, t+1, \ldots, t+n\}$ could by hired by a consortium of investors to supervise investments in the $\mathrm{n}$ periods $\{\mathrm{t}, \mathrm{t}+1, \ldots, \mathrm{t}+\mathrm{n}-1\}$, with her responsibilities and rewards in each period depending, according to some contractual plan, on her past investments' history of success or failure. To be feasible, the plan must offer nonnegative payments (limited liability) and must be incentive compatible at every period; but now the agent's anticipated rewards for success or failure of any period's investment would include the expected discounted value of all the agent's future payments under the contract after this event. The optimal incentive plans for such multi-period moral-hazard problems are characterized by the following fact, which is proven in the Appendix.

Fact 2. Consider any feasible contractual plan for a financial agent who can supervise investments in $n$ periods beginning at time $t$, and let $\mathrm{U}_{0}$ denote the expected $\mathrm{t}$-discounted value (discounted at rate $\rho$ to time $t$ ) of all payments to the agent under this plan. Then the expected t-discounted value of the surplus returns from all investments supervised by this agent cannot be greater than $\mathrm{U}_{0}\left(\mathrm{r}_{\mathrm{t}+1}+\ldots+\mathrm{r}_{\mathrm{t}+\mathrm{n}}\right) / \mathrm{M}$. This maximum is achieved by the following optimal plan: At time $\mathrm{t}$, the agent will supervise $\mathrm{h}_{0}=\mathrm{U}_{0}(1+\rho) / \mathrm{M}$; then at each time $\mathrm{t}+\mathrm{s}$ with $\mathrm{s} \in\{1, \ldots, \mathrm{n}-1\}$, the agent will supervise an investment of size $h_{s}=\left(U_{0} / M\right)(1+\rho)^{s+1} / \alpha^{s}$ if all her past 
investments from periods $\{\mathrm{t}, \ldots, \mathrm{t}+\mathrm{s}-1\}$ have succeeded, but the agent will supervise no investments after she has any failure; finally, at time $t+n$, the agent will be paid $U_{0}(1+\rho)^{\mathrm{n}} / \alpha^{\mathrm{n}}$ if she has had $\mathrm{n}$ successful investments, but otherwise she gets nothing. So the expected $\mathrm{t}$-discounted value of surplus returns from investments under this plan are indeed

$$
\begin{aligned}
\sum_{\mathrm{s} \in\{0, \ldots, \mathrm{n}-1\}} & \alpha^{\mathrm{s}} \mathrm{r}_{\mathrm{t}+\mathrm{s}+1} \mathrm{~h}_{\mathrm{s}} /(1+\rho)^{\mathrm{s}+1}=\sum_{\mathrm{s} \in\{0, \ldots, \mathrm{n}-1\}} \alpha^{\mathrm{s}} \mathrm{r}_{\mathrm{t}+\mathrm{s}+1}\left[\left(\mathrm{U}_{0} / \mathrm{M}\right)(1+\rho)^{\mathrm{s}+1} / \alpha^{\mathrm{s}}\right] /(1+\rho)^{\mathrm{s}+1} \\
& =\sum_{\mathrm{s} \in\{0, \ldots, \mathrm{n}-1\}} \mathrm{U}_{0} \mathrm{r}_{\mathrm{t}+\mathrm{s}+1} / \mathrm{M} .
\end{aligned}
$$

When investors hire a financial agent under such a contract, the investors' expected profit is equal to the expected discounted value of surplus returns from the investments supervised by the agent minus the expected discounted value of the reward payments to the agent. Facts 1 and 2 directly imply the following results about investors' profits.

Fact 3. Suppose that investors hire an agent to supervise investments in $\mathrm{n}$ periods beginning at time $t$, under a feasible contractual plan that initially gives the agent an investment $\mathrm{h}_{0}>0$ to supervise at time t. Investors can earn strictly positive expected profit from such a contract if and only if the surplus return rates satisfy $\sum_{s \in\{1, \ldots, n\}} r_{t+s}>M$. If $\sum_{s \in\{1, \ldots, n\}} r_{t+s} \leq M$ then, at time $t$, the investors' expected net profit from such a contract can be at most

$$
\mathrm{h}_{0}\left(\mathrm{r}_{\mathrm{t}+1}+\ldots+\mathrm{r}_{\mathrm{t}+\mathrm{n}}-\mathrm{M}\right) /(1+\rho) ;
$$

and this (nonpositive) maximum is achieved by the optimal plan in Fact 2 with $\mathrm{U}_{0}=\mathrm{h}_{0} \mathrm{M} /(1+\rho)$. So investors can expect to just break even in hiring financial agents under an optimal n-period incentive plan when $\sum_{\mathrm{s} \in\{1, \ldots, \mathrm{n}\}} \mathrm{r}_{\mathrm{t}+\mathrm{s}}=\mathrm{M}$.

The optimal incentive plan in Fact 2 involves maximal back-loading of rewards (to the agent's last period $\mathrm{t}+\mathrm{n}$ ) and maximal punishment of failures (termination of service without pay). With risk neutrality, all our constraints here are linear, and so it should not be surprising to find that such a corner solution is optimal. (A subsequent paper will show how results of this paper can be extended to cases of risk-averse agents; see Myerson, 2012.)

Under the optimal incentive plan, agents can be entrusted with larger investments later in their careers, as the values of their motivating end-of-career rewards become less discounted in the future. Under the formula for $h_{s}$ in Fact 2, each agent's investment responsibility is multiplied by $(1+\rho) / \alpha$ after each success. But only an $\alpha$ fraction of agents will succeed in each period. So under optimal contracts, the total responsibilities of agents who start at time $t$ must be expected to grow by a multiplicative factor of $(1+\rho)$ each period. This yields the following 
result, which is fundamental to our analysis throughout the rest of this paper.

Fact 4. Consider an economy where many consortiums of investors hire financial agents under optimal contractual plans as described in Fact 2. Assume that the number of agents is large and risks of failure are independent across different agents' investments. Then the total investments supervised by agents whose careers start at time $t$ will grow by a factor of $1+\rho$ each period until they retire at time $t+n$. That is, when $J_{t}$ is the total size of investments supervised by young agents whose n-period careers start at time t, the total size of investments supervised by agents in this cohort at time $\mathrm{t}+\mathrm{s}$ will be $\mathrm{J}_{\mathrm{t}}(1+\rho)^{\mathrm{s}}, \forall \mathrm{s} \in\{1, \ldots, \mathrm{n}-1\}$.

In the interpretation of the moral-hazard model here, there is no need to assume that the financial agents actually have any intrinsic personal connection with the investments that they supervise. It is enough to assume that financial agents have a responsibility for identifying good investment projects that belong to other entrepreneurs, so that the financial agent's only personal asset is her long-term relationship of trust with investors. For example, suppose that each potential investment project belongs to an entrepreneur who must manage it, but there are good projects with probability $\alpha$ of success and bad projects with probability $\beta$ of success. Suppose also that any entrepreneur can undetectably divert some fraction $\eta$ of the funds invested in his project, but this diversion would turn a good project into a bad one. With limited liability, to deter such diversion from a good project of size $h$, the entrepreneur must be promised a bonus $\mathrm{e}=(1+\rho) \eta \mathrm{h} /(\alpha-\beta)$ in case of success. But then the financial agent or banker, whom investors have entrusted with finding a good project, could instead substitute a bad project that belongs to a corrupt entrepreneur, from whom the banker could then demand both the $\eta$ h diversion and the bonus e as kickbacks. To deter such malfeasance, the banker's own rewards $\mathrm{v}$ and $\mathrm{w}$ for success and failure must satisfy

$$
[\alpha \mathrm{v}+(1-\alpha) \mathrm{w}] /(1+\rho) \geq \eta \mathrm{h}+[\beta(\mathrm{v}+\mathrm{e})+(1-\beta) \mathrm{w}] /(1+\rho) .
$$

This is equivalent to our basic moral-hazard incentive constraint [2] with $\gamma=\eta[1+\beta /(\alpha-\beta)]$.

Among the variables that appear in this section, the rest of this paper will use only the discount rate $\rho$, the moral-hazard coefficient $M$, and the surplus rates $r_{t+1}$. With the definitions

$$
\mathrm{r}_{\mathrm{t}+1}=\alpha \pi_{\mathrm{t}+1}-(1+\rho) \text { and } \mathrm{M}=\alpha(1+\rho) \gamma /(\alpha-\beta),
$$

the condition [1] for wrongful supervision to be uneconomical becomes

$$
0>\gamma+\beta \pi_{\mathrm{t}+1} /(1+\rho)-1=\left[\mathrm{M}(1-\beta / \alpha)+(\beta / \alpha) \mathrm{r}_{\mathrm{t}+1}\right] /(1+\rho)-(1-\beta / \alpha) .
$$


But in the equilibria of our dynamic macro model, we will always have $r_{t+1} \leq M$. So to guarantee condition [1] with any $r_{t+1} \leq M$, we need $M<(1+\rho)(1-\beta / \alpha)$. To guarantee that this inequality can be satisfied for some permissible parameters (such as $\alpha=1, \beta=0$, and $\gamma=M /(1+\rho)$ ), we henceforth assume that the expected moral-hazard rents satisfy $\mathrm{M}<1+\rho$.

\section{Equilibrium in a dynamic economy with moral hazard}

Now consider a simple economy that has just one commodity, which we may call grain. Grain can be consumed or invested at any time, but lasts only one time period. Individuals live $\mathrm{n}+1$ periods, for some positive integer $\mathrm{n}$. Each individual has risk-neutral utility for consumed grain with some time-discount rate $\rho$. The economy that we consider is on an island in a larger world, and we assume that agents can borrow or lend grain globally at the interest rate $\rho$ per period. That is, the global net supply of investment funds is perfectly elastic at interest rate $\rho$.

The only productive activities on this island are one-period investments, which take grain in any period $t$ and yield a random amount of grain in the next period $t+1$. Any such investment of size $\mathrm{h}$ in any period $\mathrm{t}$ must be supervised by a banker or financial agent who, as in the preceding section, must be promised (possibly in long-term career rewards) an expected moralhazard rent worth $\mathrm{Mh}$ at time $\mathrm{t}+1$. We assume $\mathrm{M}<1+\rho$. A banker can supervise investments on this island for up to $\mathrm{n}$ periods, after which a banker who has avoided failure can retire and consume large moral-hazard rents in the last period of her life, according to an efficient incentive plan as characterized above in Section II. Bankers need local expertise to evaluate investments, and so bankers cannot move into or out of this island during their careers.

The expected rate of return from investments on this island will depend, in each period, on the aggregate investment activity according to some investment-demand function R. That is, when $I_{t}$ is the total investment in the island at time $t$, any investment of size $h$ at time $t$ will have an expected return at time $t+1$ equal to $\left[1+\rho+R\left(I_{t}\right)\right]$ h. Here $(1+\rho) h$ is the cost at time $t+1$ of the amount $h$ invested at time $t$, and so $R\left(I_{t}\right)$ is the expected surplus return at time $t+1$, per unit invested at time $t$. This investment-demand function is assumed to make the expected surplus return rate $r_{t+1}=R\left(I_{t}\right)$ a decreasing continuous function of the total investment $I_{t}$. We assume

$$
\mathrm{R}(0)>\mathrm{M} \text { and } \lim _{\mathrm{I} \rightarrow \infty} \mathrm{R}(\mathrm{I})=0 .
$$

That is, surplus returns would be larger than the required moral-hazard rents if aggregate investment were very small, but the expected profit of investment would vanish if aggregate 
investment were very large.

We assume that, in any period, there is an unbounded supply of young qualified agents who would gladly serve as bankers supervising large investments for large expected moralhazard rents under an optimal contract as described in Facts 2-4 above. We also assume that global investors can freely organize themselves into investment consortiums that can hire such financial agents on the island at any time. (This assumption is reconsidered in Section IX.) These assumptions might seem to make it hard for this economy to get stuck in a recession caused by scarcity of trusted financial intermediaries, but we will see that such recessions can indeed occur in dynamic rational-expectations equilibria without any aggregate shocks.

At any time $\mathrm{t}$, the sum $\sum_{\mathrm{s} \in\{1, \ldots, \mathrm{n}\}} \mathbf{r}_{\mathrm{t}+\mathrm{s}}$ of expected surplus rates over the next generation cannot be larger than M. If it were then, by Fact 3, global investors could earn positive expected discounted profits from hiring more young bankers at time $t$, but the resulting increase of investments on the island would reduce rates of return during their n-period careers. Thus, in equilibrium at any time $\mathrm{t}$, we must have $\sum_{\mathrm{s} \in\{1, \ldots, \mathrm{n}\}} \mathrm{r}_{\mathrm{t}+\mathrm{s}} \leq \mathrm{M}$. Investors will be willing to hire new young bankers at time t only if $\sum_{\mathrm{s} \in\{1, \ldots, \mathrm{n}\}} \mathrm{r}_{\mathrm{t}+\mathrm{s}}=\mathrm{M}$, and then all young bankers who start their $\mathrm{n}$-period careers at time $\mathrm{t}$ will be offered optimal contracts as described in Facts 2-4 above.

Let $\mathrm{J}_{\mathrm{t}}$ denote the total investments on this island that are supervised by newly hired young bankers at time $t$. We can have $\mathrm{J}_{\mathrm{t}}>0$ only if $\sum_{\mathrm{s} \in\{1, \ldots, \mathrm{n}\}} \mathrm{r}_{\mathrm{t}+\mathrm{s}}=\mathrm{M}$. By Fact 4, under the optimal back-loaded contracts, members of the cohort who started at time $t$ will be expected to supervise total investments worth $\mathrm{J}_{\mathrm{t}}(1+\rho)^{\mathrm{s}}$ at time $\mathrm{t}+\mathrm{s}$, for each $\mathrm{s}$ in $\{0,1, \ldots, \mathrm{n}-1\}$, until they retire at time $\mathrm{t}+\mathrm{n}$. In equilibrium, investors could never expect to profit by hiring older bankers who can only serve for some smaller number of periods $\mathrm{k}$; indeed, if $\mathrm{r}_{\mathrm{t}+\mathrm{n}}>0$, investors would expect strict losses from hiring older bankers at time $\mathrm{t}$, because $\sum_{\mathrm{s} \in\{1, \ldots, \mathrm{k}\}} \mathrm{r}_{\mathrm{t}+\mathrm{s}}<\sum_{\mathrm{s} \in\{1, \ldots, \mathrm{n}\}} \mathrm{r}_{\mathrm{t}+\mathrm{s}} \leq \mathrm{M}$ when $\mathrm{k}<\mathrm{n}$. So older bankers here supervise investments only under long-term contracts that were accepted when the bankers were young.

Thus, the total investment $\mathrm{I}_{\mathrm{t}}$ on the island in any period $\mathrm{t}$ is

$$
\mathrm{I}_{\mathrm{t}}=\sum_{\mathrm{s} \in\{0,1, \ldots, \mathrm{n}-1\}} \mathrm{J}_{\mathrm{t}-\mathrm{s}}(1+\rho)^{\mathrm{s}} .
$$

These aggregate investments $I_{t}$ determine surplus return rates $r_{t+1}$ for every period $t$ through the given investment-demand function

$$
r_{t+1}=R\left(I_{t}\right) \text {. }
$$

Then our equilibrium conditions for hiring new bankers in any period $t$ are 


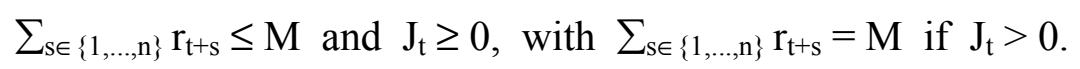

In applying these conditions [3]-[5] to define an equilibrium, we may start our analysis at some initial time, say $t=0$. At this initial time 0 , there may be some bankers of various ages who are supervising investments under pre-existing contracts with investors. Thus, the initial state of the economy at time 0 can be described by a vector $\left(\theta_{1}, \theta_{2}, \ldots, \theta_{\mathrm{n}-1}\right)$, where each $\theta_{\mathrm{s}}$ denotes the total investments that are to be supervised at time 0 by bankers of age $\mathrm{s}$, whose careers started at time $-\mathrm{s}$ and now have $\mathrm{n}-\mathrm{s}$ periods remaining. But by Fact 4, optimal contracts specify

$$
\theta_{\mathrm{s}}=\mathrm{J}_{-\mathrm{s}}(1+\rho)^{\mathrm{s}} \text { for all } \mathrm{s} \text { in }\{1, \ldots, \mathrm{n}-1\} .
$$

So the initial conditions at time 0 can be equivalently defined by specifying the starting responsibilities of the $n-1$ past cohorts of new bankers $\left(J_{-1}, J_{-2}, \ldots, J_{-(n-1)}\right)$. With these initial conditions, sequences of $\mathrm{J}_{\mathrm{t}}, \mathrm{I}_{\mathrm{t}}$, and $\mathrm{r}_{\mathrm{t}+1}$ for all $\mathrm{t} \geq 0$ together form an equilibrium of our dynamic economic model iff they satisfy conditions [3]-[5] at every period $t \geq 0$.

It is remarkable that the condition [5] for investors to hire new bankers in equilibrium depends on the simple sum of surplus rates over the next $\mathrm{n}$ periods. One might have expected the discount rate $\rho$ to appear somewhere in condition [5], but it does not. The reason is that two factors containing $\rho$ exactly cancel out in the investors' expected discounted profit calculations when they consider hiring a new young banker. As shown in Fact 2, investors discount returns s periods in the future by the factor $1 /(1+\rho)^{\mathrm{s}}$, but a new banker's responsibilities are expected to grow by the factor $(1+\rho)^{\mathrm{s}}$ in the same future period. Thus, investors can simply add up the $\mathrm{n}$ surplus rates to determine whether they can cover the required moral-hazard rents. This result depends on our assumption that investors and bankers discount future income at the same rate $\rho$.

We cannot have an equilibrium with $\mathrm{J}_{\mathrm{t}}=0$ at all $\mathrm{t} \in\{0, \ldots, \mathrm{n}-1\}$, because that would imply $I_{n-1}=0$ and $r_{n}=R(0)>M$, contradicting the first inequality in [5] (as all $r_{t+1} \geq 0$ ). So there must be some period $t \leq n-1$ when $\mathrm{J}_{\mathrm{t}}>0$ and $\sum_{\mathrm{s} \in\{1, \ldots, \mathrm{n}\}} \mathrm{r}_{\mathrm{t}+\mathrm{s}}=\mathrm{M}$. Once this equality holds, however, we can show that it must hold for all subsequent periods, and the economy's rates of return will continue in n-period cycles thereafter. This cyclical nature of equilibrium returns hold because

$$
\mathrm{r}_{\mathrm{t}+1}+\mathrm{r}_{\mathrm{t}+2}+\ldots+\mathrm{r}_{\mathrm{t}+\mathrm{n}}=\mathrm{M}=\mathrm{r}_{\mathrm{t}+2}+\ldots+\mathrm{r}_{\mathrm{t}+\mathrm{n}}+\mathrm{r}_{\mathrm{t}+1+\mathrm{n}} \text { implies } \mathrm{r}_{\mathrm{t}+\mathrm{1}}=\mathrm{r}_{\mathrm{t}+1+\mathrm{n}} \text {. }
$$

The full proof of this fact is in the Appendix.

Fact 5. In any equilibrium satisfying conditions [3]-[5], there exists some $\mathrm{T} \leq \mathrm{n}-1$ such that $\sum_{s \in\{1, \ldots, n\}} r_{t+s}=M$ for all $t \geq T$. Then surplus rates cyclically satisfy $r_{t+1}=r_{t+1+n}$ for all $t \geq T$. 
If there is an initial transient interval of time (before $T$ in Fact 5) when $\sum_{s \in\{1, \ldots, n\}} r_{t+s}$ is strictly less than $\mathrm{M}$, it would occur because the initial conditions at time 0 included large contractually stipulated investments $\left(\theta_{\mathrm{s}}\right)$ by older bankers that the investors would not have wanted to accept under the given economic parameters. (An example of this kind is shown in Section VIII.) Otherwise, returns in the economy must haves cycles of $\mathrm{n}$ periods.

Given $n$ nonnegative rates $\left(r_{1}, \ldots, r_{n}\right)$, when can there be an equilibrium (with some initial conditions) that cyclically repeats these $\mathrm{n}$ surplus-return rates with $\mathrm{r}_{\mathrm{t}}=\mathrm{r}_{\mathrm{t}+\mathrm{n}}$ for all $\mathrm{t} \geq 0$ ? By Fact 5, they must satisfy $r_{1}+\ldots+r_{n}=M$, and so the highest $r_{t+1}$ cannot be larger than M. By continuity of $R$, we can then find a corresponding cycle of investment levels $\left(\mathrm{I}_{0}, \ldots, \mathrm{I}_{\mathrm{n}-1}\right)$ that satisfy $\mathrm{r}_{\mathrm{t}+1}=\mathrm{R}\left(\mathrm{I}_{\mathrm{t}}\right)$ and $\mathrm{I}_{\mathrm{t}}=\mathrm{I}_{\mathrm{t}+\mathrm{n}}$ for all $\mathrm{t}$. If the investment-demand function is strictly decreasing then these investment levels $I_{t}$ will be uniquely determined by the rates of return $r_{t+1}$. But for this cycle to be an equilibrium with a corresponding sequence of new-banker responsibilities $J_{t} \geq 0$, there is one more set of inequalities that must be satisfied, as described in condition [7] below.

Fact 6. Given any $\mathrm{n}$ surplus rates $\left(\mathrm{r}_{1}, \ldots, \mathrm{r}_{\mathrm{n}}\right)$, the economy can have a cyclical equilibrium with $r_{t+1+n}=r_{t+1}$ for every time $t \geq 0$ if and only if the following conditions are satisfied:

$$
r_{1} \geq 0, r_{2} \geq 0, \ldots, r_{n} \geq 0, \text { and } r_{1}+r_{2}+\ldots+r_{n}=M,
$$

and there are corresponding investment levels $\left(\mathrm{I}_{0}, \mathrm{I}_{1}, \mathrm{I}_{2}, \ldots\right)$ such that

$$
r_{t+1}=R\left(I_{t}\right), I_{t+n}=I_{t} \text {, and } I_{t+1} \leq(1+\rho) I_{t} \text { for all } t \geq 0 \text {. }
$$

The corresponding new-banker responsibilities are determined by

$$
\mathrm{J}_{\mathrm{t}+1}=\left[(1+\rho) \mathrm{I}_{\mathrm{t}}-\mathrm{I}_{\mathrm{t}+1}\right] /\left[(1+\rho)^{\mathrm{n}}-1\right]=\mathrm{J}_{\mathrm{t}+1-\mathrm{n}} \text { for all } \mathrm{t} \geq 0 .
$$

The full proof of Fact 6 is in the Appendix, but we can sketch the main steps here. The cohort-decomposition equation [3] implies $(1+\rho) I_{t}-I_{t+1}=(1+\rho)^{n} J_{t+1-n}-J_{t+1}$, because all other cohorts' responsibilities grow by the factor $1+\rho$ from time $t$ to $t+1$. With cyclical $J_{t+1}=J_{t+1-n}$, we get equation [8], which with $J_{t+1} \geq 0$ implies the inequality in condition [7].

Thus we may define a credit cycle for our model to be any returns sequence $\left(\mathrm{r}_{1}, \ldots, \mathrm{r}_{\mathrm{n}}\right)$ that satisfies conditions [6] and [7] of Fact 6 . That is, the returns $r_{t}$ must be nonnegative, must satisfy the moral-hazard rents equation $r_{1}+\ldots+r_{n}=M$, and there must exist corresponding investment levels $I_{t}$ that satisfy the growth bounds $I_{t+1} \leq(1+\rho) I_{t}$. Condition [6] implies that the returns to investments in any period can never yield expected surpluses greater the bankers' required moralhazard rents; that is, $r_{t+1} \leq M$ for all $t \geq 0$. 
For any credit cycle $\left(\mathrm{r}_{1}, . ., \mathrm{r}_{\mathrm{n}}\right)$ that satisfies these conditions, the initial conditions that would make it the equilibrium of our dynamic economy are determined by the $\mathrm{J}_{\mathrm{t}}$ equations [8]. If at time 0 , for each $\mathrm{s}$ in $\{1, \ldots, n-1\}$, bankers of age $\mathrm{s}$ (with $\mathrm{n}-\mathrm{s}$ periods of service remaining in their careers) are under contract with investors to supervise aggregate investments of total size $\theta_{\mathrm{s}}=\mathrm{J}_{\mathrm{n}-\mathrm{s}}(1+\rho)^{\mathrm{s}}$, then the equilibrium of the economy will continue as in this credit cycle.

The growth bounds in condition [7] assert that aggregate investment cannot grow faster than the discount rate $\rho$. Thus, our model yields a basic asymmetry between macroeconomic growth, which must be gradual, and macroeconomic contraction, which can be steep.

Fact 5 allows that some initial conditions might not be compatible with a credit cycle that starts immediately at time 0 , but in such cases an equilibrium must have some periods with $\mathrm{J}_{\mathrm{t}}=0$ and then enter a credit cycle satisfying conditions [6]-[8]. The procedure for finding this equilibrium is described in the proof (in the Appendix) of the following existence theorem.

Fact 7. From any general initial conditions $\left(\mathrm{J}_{-1}, \ldots, \mathrm{J}_{-(\mathrm{n}-1)}\right)$, there exists an equilibrium that satisfies conditions [3]-[5] at all $\mathrm{t} \geq 0$. It consists either of a credit cycle that begins at time 0 , or else there exists some $T$ in $\{1, \ldots, n-1\}$ such that $\mathrm{J}_{\mathrm{t}}=0$ for $\mathrm{t} \in\{0, \ldots, \mathrm{T}-1\}$ and then the equilibrium continues as a credit cycle beginning at time $\mathrm{T}$.

Our economy has a steady-state solution. By condition [6], if the surplus rate $r_{t+1}$ is constant over time, it must be $\overline{\mathrm{r}}=\mathrm{M} / \mathrm{n}$, which just covers the bankers' moral-hazard rents over their n-period careers. But this steady state is the equilibrium for only one special vector of initial conditions. The model has no tendency toward steady state from other initial conditions.

Fact 8 . The steady-state equilibrium has, at all periods, the surplus return rate $\overline{\mathrm{r}}$ and aggregate investment $\overline{\mathrm{I}}$ that satisfy $\overline{\mathrm{r}}=\mathrm{M} / \mathrm{n}=\mathrm{R}(\overline{\mathrm{I}})$. This steady-state equilibrium applies when the initial conditions at time 0 are $\mathrm{J}_{-1}=\mathrm{J}_{-2}=\ldots=\mathrm{J}_{-(\mathrm{n}-1)}=\overline{\mathrm{J}}=\rho \overline{\mathrm{I}} /\left[(1+\rho)^{\mathrm{n}}-1\right]$.

\section{Interpeting the investment-demand function}

Under standard assumptions, the downward slope of the investment-demand function can be an indication of increasing costs to investors that generate income and utility for other economic agents. For example, let us consider linear investment demand functions of the form

$$
\mathrm{R}(\mathrm{I})=\max \{\mathrm{A}-\mathrm{bI}, 0\}
$$

for some positive parameters A and $\mathrm{b}$. Now suppose that the amount bI here denotes the 
expected cost of wages for workers to harvest the output of investments. That is, suppose that any investment of size $h$ at time $t$ will yield an expected gross output $(1+\rho+A) h$ at time $t+1$, but that harvesting this output will also require some labor with expected cost $b I_{t} h$ at time $t+1$. This cost could be justified by assuming that the workers' total cost of effort to harvest a total investment $\mathrm{I}_{\mathrm{t}}$ would be $0.5 \mathrm{bI}_{\mathrm{t}}{ }^{2}$. Then with a competitive labor market, the labor cost rate for harvesting at time $\mathrm{t}+1$ per unit invested at time $\mathrm{t}$ would be the workers' marginal cost $\mathrm{w}_{\mathrm{t}+1}=\mathrm{bI}_{\mathrm{t}}$. So investors' expected net returns from any investment $h$ would be $(1+\rho+A) h-w_{t+1} h=$ $\left(1+\rho+A-b I_{t}\right) h$ at time $t+1$. The workers' total wage income at time $t+1$ would then be

$$
\mathrm{W}_{\mathrm{t}+1}=\mathrm{W}_{\mathrm{t}+1} \mathrm{I}_{\mathrm{t}}=\mathrm{bI}_{\mathrm{t}}^{2} \text {, }
$$

but the workers' aggregate utility of employment, after subtracting their cost of effort, would be

$$
\mathrm{W}_{\mathrm{t}+1} \mathrm{I}_{\mathrm{t}}-0.5 \mathrm{bI}_{\mathrm{t}}^{2}=0.5 \mathrm{~W}_{\mathrm{t}+1} \text {. }
$$

We will use this measure to analyze the welfare impact of stabilization policies.

These formulas only apply in the linear case with $I_{t} \leq I^{*}=A / b$, however. More generally, when we get $\mathrm{R}\left(\mathrm{I}^{*}\right)=0$ for a finite investment level $\mathrm{I}^{*}$, some technical issues arise which we which we must now discuss.

Our analysis above assumed that, no matter how large aggregate investment might be in our economy, the appropriately supervised investment activities that were described in Section II would continue to offer some expected nonnegative surplus above the cost of invested funds (with interest). But it may be more realistic to allow that these investment activities may become unprofitable when aggregate investment goes above some critical level I* where $R\left(I^{*}\right)=0$. If aggregate investment by the bankers in our economy were greater than this amount $I^{*}$ then, as local bankers would not have profitable investments to supervise, investors might want to allow some old bankers to retire early, until such retirements reduced the aggregate investment in the economy down to $I^{*}$.

But this issue can be handled in an essentially equivalent way without introducing early retirements into our formal model. In any period when bankers' contracts specify an aggregate investment $I_{t}$ that exceeds I*, we may suppose that only $I^{*}$ will be invested in local projects of the kind described in Section II. The excess $\mathrm{I}_{\mathrm{t}}-\mathrm{I}^{*}$ would be invested in risk-free bonds at the global interest rate $\rho$, which investors would be willing to allow, as $\mathrm{R}\left(\mathrm{I}^{*}\right)=0$ means that the local investments offer no expected surplus above the $\rho$ risk-free rate. For mid-career bankers who are supervising risk-free bonds, there would be no question of success or failure, but their investment 
responsibilities and the value of their promised rewards for past successes would simply grow by the multiplicative factor $(1+\rho)$ next period (so Fact 4 can still apply). Formally, this diversion of local bankers to the global bond business would mean that, if we were considering an investment-demand function $\mathrm{R}(\mathrm{I})$ which yielded negative values for I greater than $\mathrm{I}^{*}$, then it would be effectively replaced by the adjusted investment demand function

$$
\mathrm{R}^{*}(\mathrm{I})=\max \{\mathrm{R}(\mathrm{I}), 0\}=\mathrm{R}\left(\min \left\{\mathrm{I}, \mathrm{I}^{*}\right\}\right) .
$$

With this adjusted investment-demand function $\mathrm{R}^{*}$ replacing $\mathrm{R}$, the conditions for equilibrium in [3]-[5] and [6]-[8] could be applied as before.

Such a possibility of re-assigning some local bankers to the global bond business would not change the set of credit cycles of our model, however. Given any credit cycle $\left(r_{1}, \ldots, r_{n}\right)$ that satisfies conditions [6] and [7] with investments $\left(\mathrm{I}_{0}, \mathrm{I}_{1}, \ldots\right)$ that sometimes go above $\mathrm{I}^{*}$, these

conditions can also be satisfied with the investments $\left(\hat{\mathrm{I}}_{0}, \hat{\mathrm{I}}_{1}, \ldots\right)$ where $\hat{\mathrm{I}}_{\mathrm{t}}=\min \left\{\mathrm{I}_{\mathrm{t}}, \mathrm{I}^{*}\right\}$ for all $\mathrm{t}$. In effect, the transformation from $I_{t}$ to $\hat{I}_{t}$ shifts the recruitment of some young bankers earlier in time across periods when the rates $r_{t+1}$ are 0 .

\section{An example}

For a specific numerical example, let us use the following parameters

$$
\begin{aligned}
& \rho=0.1, \alpha=0.95, \beta=0.57, \gamma=0.12, A=0.36, \text { and } b=0.327, \\
& \text { so that } M=\alpha(1+\rho) \gamma /(\alpha-\beta)=0.33, \text { and } R(I)=0.36-0.327 \mathrm{I} \text {. }
\end{aligned}
$$

It may be useful to see first how the steady-state equilibrium depends on the bankers' career length $\mathrm{n}$. With the parameters of condition [10], the steady-state surplus rate is $\overline{\mathrm{r}}=\mathrm{M} / \mathrm{n}$ $=0.33 / \mathrm{n}$, and the corresponding total investment each period is $\overline{\mathrm{I}}=(\mathrm{A}-\overline{\mathrm{r}}) / \mathrm{b}=1.10-1.01 / \mathrm{n}$. After reinvestment in steady state, the total interest payable to investors is $\rho \overline{\mathrm{I}}=0.110-0.101 / \mathrm{n}$, and the total surplus for bankers is $\overline{\mathrm{r}} \overline{\mathrm{I}}=0.363 / \mathrm{n}-0.333 / \mathrm{n}^{2}$. Under the assumptions of equation [9], harvest workers earn $\overline{\mathrm{W}}=\mathrm{b}^{2}=0.396-0.727 / \mathrm{n}+0.333 / \mathrm{n}^{2}$.

These quantities are plotted in Figure 1. The effects of changing $n$ in this simple model may look like differences between rich and poor nations. Enabling bankers to have longer relationships of trust with investors can greatly increase investment and output in this economy, as a smaller fraction of output goes to moral-hazard rents for financial intermediaries. (See Cole, Greenwood, and Sanchez, 2011.)

[Insert Figure 1 about here.] 
To be specific, let us assume that bankers' careers span $n=10$ periods. With all other parameters as in condition [10], the steady-state surplus rate is $\bar{r}=0.033$, total investment each period is $\overline{\mathrm{I}}=1$, with harvest employment yielding wage income $\overline{\mathrm{W}}=0.327$. Of this investment, the total amount supervised by new young bankers each period is $\bar{J}=\rho \bar{I} /\left[(1+\rho)^{10}-1\right]=0.063$. The total amount supervised by older bankers with s periods of experience is $\Theta_{\mathrm{s}}=\overline{\mathrm{J}}(1+\rho)^{\mathrm{s}}$. The steady-state distribution of investments by these age cohorts is

$$
\left(\Theta_{1}, \ldots, \Theta_{9}\right)=(0.069,0.076,0.084,0.092,0.101,0.111,0.122,0.135,0.148) .
$$

Now, with $\mathrm{n}=10$ and all other parameters as in condition [10], let us analyze a dynamic equilibrium from initial conditions at time 0 where the investments supervised by older bankers are $80 \%$ of the steady-state $\Theta_{\mathrm{s}}$ above. (Such a situation could occur, for example, if the economy was in a steady state before an unanticipated technical change at time 0 increased investment demand by a permanent $20 \%$ reduction of the parameter $b$, to 0.327 .) So at time 0 , the total contractually-mandated investments $\theta_{\mathrm{s}}$ for continuing mid-career bankers of each age $\mathrm{s}$ are

$$
\left(\theta_{1}, \ldots, \theta_{9}\right)=(0.055,0.061,0.067,0.073,0.081,0.089,0.098,0.108,0.118) .
$$

These all correspond to initial responsibilities $J_{-s}=\theta_{s} /(1+\rho)^{\mathrm{s}}=0.050$ for each $\mathrm{s}$ in $\{1, \ldots, 9\}$.

To compute the equilibrium that evolves from these initial conditions, we only need to find $\mathrm{J}_{0}$, the total investments that new bankers make at time 0 . The contractual investments of each cohort grow by the multiplicative factor $(1+\rho)$ each period until the cohort retires at age $n$; and then it must be replaced by a new cohort whose new investments will equal the final investment of the old retiring cohort divided by $(1+\rho)^{\mathrm{n}-1}$, so that the new cohort will repeat the retiring cohort's investments $\mathrm{n}$ periods later. Any increase of $\mathrm{J}_{0}$ would increase all future investments $I_{t}$ and so would decrease all future returns $r_{t+1}=R\left(I_{t}\right)$. In equilibrium, we must have $\mathrm{r}_{1}+\ldots+\mathrm{r}_{10}=\mathrm{M}$, as in equation [6], and this equation here has the solution $\mathrm{J}_{0}=0.176$. The resulting 10-period credit cycle is shown in Figure 2.

\section{[Insert Figure 2 about here]}

In this equilibrium, the shortage of bankers at time 0 causes a large cohort of new bankers to enter and handle investment $\mathrm{J}_{0}=0.176$, which is 2.8 times larger than the steady-state $\overline{\mathrm{J}}=0.063$ that we found above. At time 1, the surplus-return rate is $r_{1}=0.057$, total output at time 1 is $7.5 \%$ below steady state, and wage income $\mathrm{W}_{1}=\mathrm{bI}_{0}{ }^{2}=0.280$ is $14 \%$ below steady state. Thereafter, in the shadow of the large $\mathrm{J}_{0}$, subsequent cohorts of young bankers are smaller, with $\mathrm{J}_{\mathrm{t}}=0.050$ for $\mathrm{t}=1,2, \ldots, 9$. The economy gradually grows, and just reaches steady-state output at time 6 . 
Thereafter, the growing investments of the large cohort of bankers that entered at time 0 put the economy into a boom with investment and output greater than in the steady state, reaching a peak at time 10 , when a low surplus-return rate $r_{10}=0.0016$ yields output $9.6 \%$ above steady state and wage income $20 \%$ above the steady state.

But at time 10, the generation-0 bankers retire and consume their accumulated profits, thus creating a new scarcity of investment intermediaries. Then new investment at time 10 drops in a recession to the same level as at time 0 , and the cycle repeats itself.

\section{Evaluating the benefits of subsidies for financial stabilization}

In the context of the above example, let us consider the consequences of a financial intervention by the government to stabilize the economy at the steady state. To achieve steadystate stability here at time 0 , new investment consortiums must hire enough older bankers to restore the steady-state profile of age-cohort investments $\Theta_{\mathrm{s}}$ shown above. That is, for each $\mathrm{s}$ in $\{1, \ldots, 9\}$, bankers of age s must be given new investments equal to $\Theta_{\mathrm{s}}-\theta_{\mathrm{s}}$. But at steady-state returns $\overline{\mathrm{r}}=\mathrm{M} / \mathrm{n}$, these new investments with bankers who can only serve $\mathrm{n}-\mathrm{s}$ periods would (by Fact 3) incur expected losses worth $\left(\Theta_{\mathrm{s}}-\theta_{\mathrm{s}}\right)[\mathrm{M}-(\mathrm{n}-\mathrm{s}) \overline{\mathrm{r}}] /(1+\rho)=\left(\Theta_{\mathrm{s}}-\theta_{\mathrm{s}}\right)(\mathrm{sM} / \mathrm{n}) /(1+\rho)$ at time 0 . For stabilization, then, the new investors who hire older bankers must get a subsidy which at time 0 would be worth

$$
\sum_{\mathrm{s} \in\{1, \ldots, 9\}}\left(\Theta_{\mathrm{s}}-\theta_{\mathrm{s}}\right)(\mathrm{sM} / \mathrm{n}) /(1+\rho)=0.032 .
$$

This subsidy can be financed by selling bonds to be repaid with interest $\rho$ by 0.035 from lump-sum taxes on the workers at time 1. The cost of this subsidy is less than the increase in wage income $0.327-0.280=0.047$ that the workers get from the stabilization at time 1 . The workers' utility gains here are only half of their wage gains (because of their quadratic cost of effort), but the wage gains continue for 5 time periods. At time 1, the total discounted values of future utility gains from stabilization for workers who have 1 to 10 periods of employment remaining in their careers (with each active cohort supplying 1/10 of total labor) are respectively:

$$
(0.0023,0.0041,0.0054,0.0062,0.0066,0.0065,0.0061,0.0053,0.0042,0.0029) \text {. }
$$

Middle-aged workers gain the most here. Old workers have less future time to gain, and stabilization eliminates benefits of a future boom for young workers. Summing, we find that the time-1 workers' total long-run gains from stabilization (0.049) exceed its cost (0.035) here.

Other examples can be found where stabilization subsidies are not worth the expense for 
tax-paying workers, however, and it seems difficult to characterize the cases where it is worthwhile. Also, replacing lump-sum taxes by more realistic taxes on income can introduce distortions that reduce aggregate welfare. So next let us consider instead the effect of a small short-term balanced fiscal stimulus that is financed by taxes on investment income.

\section{Effects of a small short-term balanced fiscal stimulus}

Consider stimulating the economy in one period, say period 0 , by government-subsidized investments which do not use long-term relationships with financial agents and so will not generate any competition with future bankers in the economy. Such investments still need to solve moral-hazard problems in financial intermediation, and so they must use financial agents who will get expected moral-hazard rents $M$ at time 1 per unit invested at time 0 . Such shortterm investment supervision is more expensive, and it so can only be done as a governmentsubsidized activity, which must be financed by some form of taxes. We may refer to such government-subsidized investment with one-period supervision as Keynesian investment. In such investment, the lack of a long-term financial relationship with the supervising agents may appear inefficient, but it has the dynamic advantage of increasing investment now without crowding out future growth of financial intermediation.

Now let us make the more realistic assumption that the subsidies for this Keynesian investment are financed by taxes on real productive activity (rather than by lump-sum taxes as in the previous section). These taxes will have offsetting effects of inhibiting some economic activity in the period when they are collected. It should not be surprising that production in the economy at time 0 could be increased by such subsidized short-term investment if it is financed by taxes in distant future periods, through an issue of long-term debt at time 0 . So to get a more interesting perspective, let us assume that the short-term fiscal stimulus at time 0 will be financed directly by taxes on the output of private investment from time 0 itself. These taxes will be collected at time 1, when the output of period-0 investment is realized. Keynesian investment with such current tax financing may be called a short-term balanced fiscal stimulus.

To model such a short-term balanced fiscal stimulus at time 0 , let $\tau$ be the expected rate of taxes on output at time 1 , per unit invested at time 0 . Let $\mathrm{I}_{0}$ denote the regular (unsubsidized) private investment at time 0 , and let $\mathrm{K}_{0}$ denote the additional short-term Keynesian investment that is financed by these taxes. The pre-tax surplus returns on investments at time 1 will be

$$
\mathrm{r}_{1}=\mathrm{R}\left(\mathrm{K}_{0}+\mathrm{I}_{0}\right)=\mathrm{R}\left(\mathrm{K}_{0}+\mathrm{J}_{0}+\sum_{\mathrm{s} \in\{1, \ldots, \mathrm{n}-1\}} \mathrm{J}_{-\mathrm{s}}(1+\rho)^{\mathrm{s}}\right),
$$


but the net surplus return to private investment after taxes will be $r_{1}-\tau$. The short-term Keynesian investment at time 0 will require, at time 1 , a net tax-financed subsidy of $\mathrm{M}-\mathrm{R}\left(\mathrm{I}_{0}+\mathrm{K}_{0}\right)$ per unit invested, and so the balanced fiscal budget constraint is

$$
\mathrm{K}_{0}=\tau \mathrm{I}_{0} /\left(\mathrm{M}-\mathrm{r}_{1}\right)=\tau\left(\mathrm{J}_{0}+\sum_{\mathrm{s} \in\{1, \ldots, \mathrm{n}-1\}} \mathrm{J}_{-\mathrm{s}}(1+\rho)^{\mathrm{s}}\right) /\left(\mathrm{M}-\mathrm{r}_{1}\right) .
$$

Assuming that the fiscal stimulus is only for this one period, we have the usual equilibrium equations for all $\mathrm{t} \geq 2$ :

$$
\mathrm{r}_{\mathrm{t}}=\mathrm{R}\left(\mathrm{I}_{\mathrm{t}-1}\right)=\mathrm{R}\left(\sum_{\mathrm{s} \in\{1,2, \ldots, \mathrm{n}\}} \mathrm{J}_{\mathrm{t}-\mathrm{s}}(1+\rho)^{\mathrm{s}-1}\right), \mathrm{J}_{\mathrm{t}}=\mathrm{J}_{\mathrm{t}-\mathrm{n}}, \text { and } \sum_{\mathrm{s} \in\{1,2, \ldots, \mathrm{n}\}} \mathrm{r}_{\mathrm{t}+\mathrm{s}}=\mathrm{M}, \quad \forall \mathrm{t} \geq 2 .
$$

Here $\left(\mathrm{J}_{-1}, \ldots, \mathrm{J}_{-(\mathrm{n}-1)}\right)$ are given as initial conditions at time 0 , and so these equations depend on just two unknowns: $\mathrm{J}_{0}$ and $\mathrm{J}_{1}$. These new-cohort investment amounts are determined by the moralhazard rent equations for the hiring of new agents at times 0 and 1 :

$$
\left(r_{1}-\tau\right)+r_{2}+\ldots+r_{n}=M=r_{2}+\ldots+r_{n}+r_{n+1} \text {, and so } r_{1}-\tau=r_{n+1} .
$$

\section{[Insert Figure 3 about here]}

Figure 3 shows the result of a small short-term balanced fiscal stimulus in our example from the preceding two sections, with the tax rate $\tau=0.015$. Where period- 0 investment without the stimulus would be $\mathrm{I}_{0}=0.925$, the stimulus adds Keynesian investment $\mathrm{K}_{0}=0.048$ while reducing private investment by 0.040 to $\mathrm{I}_{0}=0.886$. So the stimulus increases total investment $\mathrm{I}_{0}+\mathrm{K}_{0}$ at time 0 , which is then only $6.6 \%$ below steady state (instead of $7.5 \%$ without the stimulus). The private investment that is crowded out by the stimulus is all in reduced investment by new young bankers at time 0 (reducing $\mathrm{J}_{0}$ from 0.176 to 0.136 ), but then investment by new young bankers $J_{1}$ in the next period will increase by the same amount. Then peak investment at period 9 is $8.7 \%$ above steady state (instead of $9.6 \%$ without the stimulus).

More generally, the following fact (proven in the Appendix) lists some readily verifiable conditions under which the introduction of a small positive tax $\tau$ on the investments of period 0 would finance more Keynesian investment $\mathrm{K}_{0}$ than it displaces from private investment $\mathrm{I}_{0}$ and so would yield a net increase of total investment $\mathrm{I}_{0}+\mathrm{K}_{0}$.

Fact 9. Assume a linear investment-demand function $\mathrm{R}(\mathrm{I})=\mathrm{A}-\mathrm{bI}$, and consider an equilibrium credit cycle such that $I_{t} \leq A / b$ for all $t$. If $A>M$ and $(1+\rho)^{n-1}>2$ then a small short-term balanced fiscal stimulus at time 0 would increase total current investment $\mathrm{I}_{0}+\mathrm{K}_{0}$.

The analysis here relies critically on an assumption that the stimulus would not be anticipated by investors, and would not induce expectations of other such interventions in the 
future. As the stimulus reduces investors' net surplus $r_{1}-\tau$ from investments at time 0 , it may make the pre-existing investment contracts unprofitable. If this had been anticipated by investors, they might not have hired some of the bankers who are in mid-career at time 0 . Thus, some of the benefits of the stimulus at time 0 may come at the expense of past investors.

\section{Other equilibrium scenarios}

In Section VI we considered an example with bankers starting 20\% below their steadystate levels. Now let us consider the same example but with all continuing cohorts of bankers at time 0 supervising investments $20 \%$ larger than in steady-state. So we have $n=10$ and all other parameters as in condition [10], but reinvestments $\theta_{\mathrm{s}}$ for bankers of each age $\mathrm{s}$ at time 0 are now

$$
\left(\theta_{1}, \ldots, \theta_{9}\right)=(0.083,0.091,0.100,0.110,0.121,0.133,0.147,0.161,0.178) .
$$

These all correspond to initial investments $J_{-s}=\theta_{s} /(1+\rho)^{\mathrm{s}}=0.075$ for each $\mathrm{s}$ in $\{1, \ldots, 9\}$.

The dynamic equilibrium for these initial conditions satisfies Fact 7 with a credit cycle starting at $\mathrm{T}=1$. If we apply the initial cyclical assumption that $\mathrm{J}_{\mathrm{t}}=\mathrm{J}_{\mathrm{t}-\mathrm{n}}$ for all $\mathrm{t} \geq 1$, we find that even $\mathrm{J}_{0}=0$ yields surplus rates $\mathrm{r}_{\mathrm{t}+1}=\mathrm{R}\left(\sum_{\mathrm{s} \in\{0, \ldots, \mathrm{n}-1\}} \mathrm{J}_{\mathrm{t}-\mathrm{s}}(1+\rho)^{\mathrm{s}}\right)$ such that $\mathrm{r}_{1}+\ldots+\mathrm{r}_{\mathrm{n}}<\mathrm{M}$. The problem is that the reinvestment agreements for older bankers are too large for any new bankers to be profitably hired in this economy at time 0 . So we let $\mathrm{J}_{0}=0$ and we drop the assumption that $\mathrm{J}_{1}$ should be the same as $\mathrm{J}_{1-\mathrm{n}}=\mathrm{J}_{-9}$. Then, applying the cyclical assumption $\mathrm{J}_{\mathrm{t}}=\mathrm{J}_{\mathrm{t}-\mathrm{n}}$ for $\mathrm{t} \geq 2$, we find that $J_{1}=0.025$ yields surplus rates satisfying $r_{t+1}+\ldots+r_{t+n}=M$ for all $t \geq 1$. Then a credit cycle begins at time 1, as shown in Figure 4.

\section{[Insert Figure 4 about here]}

In Figure 4, the high investment amount $\mathrm{I}_{0}$ at time 0 is a transient phenomenon which is not repeated in any subsequent period, but $\mathrm{I}_{\mathrm{t}}=\mathrm{I}_{\mathrm{t}+\mathrm{n}}$ for all $\mathrm{t} \geq 1$. Aggregate investment declines slowly from time 0 to time 9 . Thereafter, in each subsequent pass through the 10 -period cycle, the economy grows strongly in the first two periods, as the small cohorts retire, but then the economy drops into another long slow recession, as the large cohorts retire. Investment is 6.7\%

above the steady state at the top of the cycle (at times 11,21 , etc), but it is $8.5 \%$ below the steady state at the bottom of the cycle (at times 9, 19, etc.).

This example represents an economy that has inherited a banking system that is too large to be sustainable. The large cohorts of old bankers can keep investment above the steady state for several periods, but only as the start of a long economic decline. This model of "zombie" 
bankers, continuing beyond their natural economic lives, might be interpreted as a simple model of Japan's lost decade after the collapse of the 1980s boom.

Finally, let us consider what would happen in the worst-case scenario when the economy starts at time 0 with no bankers at all, so that $\theta_{\mathrm{s}}=0$ for all $\mathrm{s}$ in $\{1, \ldots, \mathrm{n}-1\}$. From this initial condition, with parameters as above in condition [10], the equilibrium credit cycle starts with low investment $\mathrm{I}_{0}=\mathrm{J}_{0}=0.736$ and a high surplus rate $\mathrm{r}_{1}=0.119$. Investment then grows at the maximal rate $\rho$ for 4 periods and thereafter levels off at a peak where $I_{t}=1.10$ and $r_{t+1}=0$, which continues from time $\mathrm{t}=5$ onwards, with no new entry of bankers, until the generation- 0 bankers retire at time $\mathrm{n}$. Thus, output at the trough in this worst-case scenario is $33 \%$ less than output at the peak, which takes 5 periods to reach from the trough. Remarkably, this result does not depend on the parameter $n$, as long as $n>5$. That is, the potential depth and duration of recessions in our model do not depend on the length of the bankers' careers. With larger $n$, the economy could spend more time in the peak boom where $r_{t+1}=0$, but the bankers' moral-hazard rents must ultimately be paid from surplus returns in the periods near the trough.

\section{The problem of liquidity for investors}

In this section, we reconsider our model's basic assumption that bankers are hired by consortiums of investors with long-term contracts. Consider a midcareer banker whose career started at time $t$, and who is supervising an investment of size $h_{s}$ at time $t+s$ under such a contract. By Fact 3, the expected discounted value of profits for the banker's investors under the optimal back-loaded incentive plan is

$$
\mathrm{h}_{\mathrm{s}}\left(\mathrm{r}_{\mathrm{t}+\mathrm{s}+1}+\ldots+\mathrm{r}_{\mathrm{t}+\mathrm{n}}-\mathrm{M}\right) /(1+\rho) .
$$

When the banker was first hired, the $\mathrm{n}$ future surplus rates summed to M. So now (when $\mathrm{s}$ nonnegative surplus rates have become things of the past), the sum of the n-s surplus rates in the remainder of the banker's career will typically be less than M. So the investors' expected discounted value of profits from their future service from a midcareer banker is typically negative. This profit calculation takes account of the cost of the current investment $h_{s}$, future reinvestments, and the cost of a promised retirement bonus for the banker if successful. That is, after deducting the cost of the banker's moral-hazard rents, the total expected discounted value of all net dividends that the investors can earn from their future investments with the midcareer banker is less than the amount $h_{s}$ that they are re-investing with the banker. If the investors could terminate their relationship with the banker after her first successful investment without paying 
her any moral-hazard rents, they would do so. So our economy depends critically on an assumption that investors can be contractually committed to fulfill the obligations of their longterm relationship with their banker or financial agent.

Thus, although the productive investments in this economy are all short term (spanning just one period), moral hazard in financial intermediation requires investors to make a long-term (n-period) commitment to their banker or financial agent. In this sense, moral hazard in financial intermediation can induce investors to accept a kind of illiquidity in their investments. This illiquidity has been implicit in our model of financial agents being hired by consortiums of investors, whose relationship with the banker or financial agent could be viewed as constituting a closed-end mutual fund to operate over $\mathrm{n}$ periods.

With regulation, however, these dynamic equilibria could be equivalently implemented by an alternative financial-intermediation system in which investors hold liquid short-term investments with bankers who are required to invest some proportionate amount of their own capital, under a capital-ratio requirement that depends on the banker's age. In this system, the bankers accumulate capital during their careers, and this capital is invested by older bankers to cover part of the costs of their own moral-hazard rents.

For investors to voluntarily participate in a short-term investment of size $\mathrm{h}$ supervised by the banker of age $s$ at time $t+s$, the expected net loss that we calculated above [11] must be provided by the banker herself. That is, to invest $h_{s}$ at time $t+s$ with voluntary short-term participation by outside investors, the banker of age $\mathrm{s}$ must contribute capital $\mathrm{k}_{\mathrm{s}}$ such that

$$
\mathrm{k}_{\mathrm{s}}=\mathrm{h}_{\mathrm{s}}\left[\mathrm{M}-\left(\mathrm{r}_{\mathrm{t}+\mathrm{s}+1}+\ldots+\mathrm{r}_{\mathrm{t}+\mathrm{n}}\right)\right] /(1+\rho) .
$$

In equilibrium, this formula requires no capital from a young banker when $\mathrm{s}=0$, at the start of her n-period career. The expected normal returns to investors in the next period would have to be $\left(h_{s}-k_{s}\right)(1+\rho)$, and so the expected total capital for the banker at time $t+s+1$ would be

$$
\mathrm{k}_{\mathrm{s}+1}=\left(1+\rho+\mathrm{r}_{\mathrm{t}+\mathrm{s}+1}\right) \mathrm{h}_{\mathrm{s}}-\left(\mathrm{h}_{\mathrm{s}}-\mathrm{k}_{\mathrm{s}}\right)(1+\rho)=\mathrm{k}_{\mathrm{s}}(1+\rho)+\mathrm{r}_{\mathrm{t}+\mathrm{s}+1} \mathrm{~h}_{\mathrm{s}}=\mathrm{h}_{\mathrm{s}}\left[\mathrm{M}-\left(\mathrm{r}_{\mathrm{t}+\mathrm{s}+2}+\ldots+\mathrm{r}_{\mathrm{t}+\mathrm{n}}\right)\right] .
$$

In our equilibria, bankers' expected responsibilities are multiplied by $(1+\rho)$ every period during their careers. Under this alternative system, the banker's expected capital at time $t+s+1$ is exactly what is needed to finance the same expected investment $h_{s+1}=h_{s}(1+\rho)$ when her required share of the investment will be $\mathrm{h}_{\mathrm{s}+1}\left[\mathrm{M}-\left(\mathrm{r}_{\mathrm{t}+\mathrm{s}+2}+\ldots+\mathrm{r}_{\mathrm{t}+\mathrm{n}}\right)\right] /(1+\rho)$. Finally, at time $\mathrm{t}+\mathrm{n}$, the banker's final expected return would be $k_{n-1}(1+\rho)+r_{t+n} h_{n-1}=h_{n-1} M$, which is her required moral-hazard rent.

Some regulation may be needed to verify that bankers always have the required amount 
of capital in their investments. But there is another fundamental reason for regulation to sustain this financial-intermediation system in which investors are free to liquidate their investments at any time. Under this system, in each period before the end, the banker is being paid in units of bank capital that can earn expected rates of return higher than the global risk-free rate $\rho$, which makes the bankers' rewards from success more valuable. But this system essentially depends on an implicit assumption that, in the banker's incentive constraint, the illegitimate earnings from wrongful behavior could not also be invested as bank capital. That is, in the basic incentive constraint [2] from Section II, someone must make sure that the capital that the banker can leverage with investors in the next period will include only her legitimate rewards ( $\mathrm{v}$ and $\mathrm{w}$ in [2]). The banker must not be able to include any illegitimate rewards from wrongful behavior (the term $\gamma \mathrm{h}$ in [2]) in her bank capital in the next period. As new short-term investors next period will not care how their banker earned her capital, this restriction of capital to legitimate earnings could require external legal enforcement.

\section{Considering the possibility of stochastic macroeconomic shocks}

In our model, we have found boom-and-bust credit cycles without any macroeconomic shocks. Still, one might ask, what if we added a possibility of stochastic macroeconomic shocks that affect the distribution of returns to all investments? Such shocks would be publicly observable ex post, and so investors should be able to condition their agents' career rewards on the occurrence of such shocks, as well as on the observable results of each agent's individual investments. In a rational-expectations equilibrium, we should assume that investors and agents understand the probability distribution of these shocks.

To analyze such a model, we must go back to extend the moral-hazard framework of Section II. In a moral-hazard model, the agents' optimal rewards in any observable outcome must depend on the likelihood ratio of the outcome when the agent behaves appropriately or wrongly. With risk-neutrality and limited liability, the optimal rewards for a young agent should be concentrated in the case where this likelihood ratio is maximal. (For example, see Tirole, 2006, p. 118.) Thus, if we introduced a possible alternative ex-post-observable macroeconomic state in which returns to investments may differ, then the dynamics of our economy would depend not only on the probability of success when agents behave well, but also on the probability of success when agents behave badly, even though in equilibrium nobody is supposed to behave badly. Without going deeply into this complex issue, let us briefly consider here one 
example that illustrates the complications that arise when we introduce this issue.

Consider a numerical example as above in condition [10] (but perhaps with $n=2$ and a higher $\rho$ ). The normal probability of success is $\alpha=0.95$ if the agent acts appropriately but is $\beta=0.57$ if the agent acts wrongly (to take a hidden benefit of $\gamma=12 \%$ of the invested funds). Now

perturb the model by adding a small $\varepsilon$ probability of an alternative macroeconomic state in which the probability of success for any investment would be $\alpha^{\prime}=0.951$ when agents act appropriately (so that investors can recognize an occurrence of this state by the slightly elevated aggregate rate of successful investments) but would also be $\beta^{\prime}=0.951$ also if agents acted wrongly. In this case, success in the alternative macroeconomic state would not be evidence of good behavior, and so optimal contracts would terminate all young bankers regardless of their investments' success or failure when this state occurs. That is, even though there has been no loss of output, the occurrence of this alternative macroeconomic state could, if rationally anticipated in optimal agency contracts, result in the economy losing an entire cohort of age-1 bankers. (On the other hand, if we specified $\beta^{\prime}=0.001$ instead, then optimal contracts for risk-neutral young agents would tend to increase promised career rewards in this alternative state until subsequent surpluses were driven down substantially below the normal state.) Thus, an apparently small one-period shock to investment outcomes $\alpha$ could, when it is rationally anticipated in optimal agency contracts, induce new forms of instability in the system of financial intermediation.

\section{Conclusions}

Financial crises and recessions are vast complex phenomena, but their inexorable momentum must be derived from factors that are fundamental in economic systems. Theoretical models are tools that can help us see what these driving factors might be. In this paper, we analyzed a theoretical model to show how moral hazard in financial intermediation can cause aggregate economic fluctuations, even in a stationary economic environment without money or long-term assets.

The key to our analysis is that, to efficiently solve financial moral-hazard problems, bankers must form some kind of long-term relationship with communities of investors. The state of these relationships can create complex dynamics, even in an economy that is otherwise completely stationary. These dynamics are driven by the basic fact that, at any point in time, investors' ability to trust their bankers depends critically on expectations of future profits in 
banking. Cyclically changing expectations can rationally sustain an equilibrium cycle of booms and recessions. Our economic model has a steady-state solution, but it is the dynamic equilibrium only for one special vector of initial conditions, and the model has no tendency toward steady state from other initial conditions.

In the recessions of our model, aggregate production declines as productive investment is reduced by a scarcity of trusted financial intermediaries. Competitive recruitment of new bankers cannot fully remedy such an undersupply of financial intermediaries, because moralhazard constraints imply that bankers can be hired efficiently only as part of a long-term career plan in which the bankers' expected responsibilities tend to grow during their careers. Because of this expected growth of bankers' responsibilities, a large adjustment to reach steady-state financial capacity in one period would create excess financial capacity in future periods. Thus, a financial recovery must drive gradually uphill into the next boom, when the economy will have an excess of financial intermediaries relative to what can be sustained in the steady state, and this boom can in turn contain the seeds of a future recession.

A stabilization that shifts the economy from such a recession to the steady state would require some new investments to be handled by older bankers who are more expensive, because their moral-hazard rents cannot be distributed over as many periods of future investment. Investors would be unwilling to use these costly shorter-term intermediaries without a subsidy. But we found that, in some cases, the workers' benefits from such macroeconomic stabilization may be greater than the cost of the required subsidies. In this sense, a tax on poor workers to subsidize rich bankers may actually benefit the workers, as the increase of investment and employment can raise their wages by more than the cost of the tax. Some of these wage increases, however, would come at the expense of other investors who must re-invest past earnings under previously negotiated financial contracts.

\section{Appendix: Longer proofs}

Proof of Fact 2. Fact 1 implies that, in any period when the agent supervises an investment $h$, the expected discounted value of the agent's future rewards be at least $\mathrm{Mh} /(1+\rho)$. But the expected value of the rewards paid at or after time $t+s+1$, discounted to time $t+s$, cannot be greater than $U_{0}(1+\rho)^{\mathrm{s}}$, because $U_{0}$ is the expected value of all payments discounted to time $t$, and all payments to the agent are nonnegative. So the expected size of the investment supervised 
by the agent at time $t^{+} \mathrm{s}$ cannot be greater than $\mathrm{U}_{0}(1+\rho)^{\mathrm{s}+1} / \mathrm{M}$, for any $\mathrm{s}$ in $\{0, \ldots, \mathrm{n}-1\}$. Thus, the expected t-discounted value of the surplus returns from investments supervised by the agent in her n-period career cannot be greater than

$$
\sum_{s \in\{0, \ldots, n-1\}} r_{t+s+1}\left[U_{0}(1+\rho)^{s+1} / M\right] /(1+\rho)^{s+1}=\sum_{s \in\{0, \ldots, n-1\}} U_{0} r_{t+s+1} / M .
$$

Under the optimal plan described in Fact 2, the agent at time $t+s$ will supervise either an investment of size $\left(U_{0} / M\right)(1+\rho)^{s+1} / \alpha^{\mathrm{s}}$ with probability $\alpha^{\mathrm{s}}$, or else 0 ; so the expected investment size at each time $\mathrm{t}+\mathrm{s}$ achieves this upper bound $\mathrm{U}_{0}(1+\rho)^{\mathrm{s}+1} / \mathrm{M}$.

Finally we must verify that this optimal plan satisfies the moral-hazard incentive constraints at each time $\mathrm{t}+\mathrm{s}$ when the agent has not yet failed and is handling an investment of size $h_{s}=\left(U_{0} / M\right)(1+\rho)^{s+1} / \alpha^{s}$. If this investment succeeds then, at time $t^{t}+s+1$, the agent will be in a contractual position to earn $\mathrm{U}_{0}(1+\rho)^{\mathrm{n}} / \alpha^{\mathrm{n}}$ after $\mathrm{n}-\mathrm{s}-1$ periods if the next $\mathrm{n}-\mathrm{s}-1$ investments succeed, which has probability $\alpha^{\mathrm{n}-\mathrm{s}-1}$; and so the expected discounted value of this position for the agent at time $\mathrm{t}+\mathrm{s}+1$ will be $\alpha^{\mathrm{n}-\mathrm{s}-1}\left[\mathrm{U}_{0}(1+\rho)^{\mathrm{n}} / \alpha^{\mathrm{n}}\right] /(1+\rho)^{\mathrm{n}-\mathrm{s}-1}=\mathrm{h}_{\mathrm{s}} \mathrm{M} / \alpha$. On the other hand, if this investment fails then the agent's position will be worth 0 at time $t+s+1$. So the contractually promised career rewards at time $\mathrm{t}+\mathrm{s}+1$ constitute an incentive-compatible plan that essentially matches the plan described in Fact 1 for the investment $\mathrm{h}=\mathrm{h}_{\mathrm{s}}$.

Proof of Fact 3. Let $\mathrm{U}_{0}$ denote the agent's initial expected discounted value of rewards under the given contract. By Fact 2, the investors' expected profit can be at most

$$
\mathrm{U}_{0}\left(\mathrm{r}_{\mathrm{t}+1}+\ldots . \mathrm{r}_{\mathrm{t}+\mathrm{n}}\right) / \mathrm{M}-\mathrm{U}_{0}=\left(\mathrm{U}_{0} / \mathrm{M}\right)\left(\mathrm{r}_{\mathrm{t}+1}+\ldots . \mathrm{r}_{\mathrm{t}+\mathrm{n}}-\mathrm{M}\right) .
$$

By Fact 1, the investment $h_{0}$ at time $t$ requires $U_{0} \geq h_{0} M /(1+\rho)$. So when $r_{t+1}+\ldots . r_{t+n} \leq M$, the investors' expected profit is nonpositive and so is maximized by the minimal $\mathrm{U}_{0}=\mathrm{h}_{0} \mathrm{M} /(1+\rho)$.

Proof of Fact 5. Suppose to the contrary that there is some time $\mathrm{z}$ such that $\sum_{\mathrm{s} \in\{1, \ldots, \mathrm{n}\}} \mathrm{r}_{\mathrm{z}+\mathrm{s}}=\mathrm{M}$ but $\sum_{\mathrm{s} \in\{1, \ldots, \mathrm{n}\}} \mathrm{r}_{\mathrm{z}+1+\mathrm{s}}<\mathrm{M}$. This strict inequality cannot continue for $\mathrm{n}$ periods after $z$, or else $I_{z+n}$ would be 0 and $R\left(I_{z+n+1}\right)$ would be larger than $M$. So there must be some $y$ such that $2 \leq \mathrm{y} \leq \mathrm{n}$ and $\sum_{\mathrm{s} \in\{1, \ldots, \mathrm{n}\}} \mathrm{r}_{\mathrm{z}+\mathrm{x}+\mathrm{s}}<\mathrm{M} \forall \mathrm{x} \in\{1, \ldots, \mathrm{y}-1\}$, but $\sum_{\mathrm{s} \in\{1, \ldots, \mathrm{n}\}} \mathrm{r}_{\mathrm{z}+\mathrm{s}}=\mathrm{M}$ and $\sum_{\mathrm{s} \in\{1, \ldots, n\}} \mathrm{r}_{\mathrm{z}+\mathrm{y}+\mathrm{s}}=\mathrm{M}$. When the $\mathrm{n}-\mathrm{y}$ common terms from these two sums are pulled out of these two equations, we get

$$
\mathrm{r}_{\mathrm{z}+1}+\ldots+\mathrm{r}_{\mathrm{z}+\mathrm{y}}=\mathrm{r}_{\mathrm{z}+1+\mathrm{n}}+\ldots+\mathrm{r}_{\mathrm{z}+\mathrm{y}+\mathrm{n} .}
$$

But we must also have $\mathrm{J}_{\mathrm{z}+\mathrm{x}}=0 \quad \forall \mathrm{x} \in\{1, \ldots, \mathrm{y}-1\}$. The fact that there is no hiring of new bankers from time $\mathrm{z}^{+1}$ to $\mathrm{z}^{+} \mathrm{y}$ implies that $\mathrm{I}_{\mathrm{z}^{+} \mathrm{x}} \leq \mathrm{I}_{\mathrm{z}}(1+\rho)^{\mathrm{x}}$ for all $\mathrm{x}$ in $\{1, \ldots, \mathrm{y}-1\}$. (This upper bound 
represents investment at time $z^{+} x$ with mid-career responsibilities growing at rate $(1+\rho)$, as specified by Fact 4, but no retirements.) Similarly, the fact that there will be no retirements of old bankers from time $\mathrm{z}+1+\mathrm{n}$ to $\mathrm{z}+\mathrm{y}+\mathrm{n}$ implies that $\mathrm{I}_{\mathrm{z}+\mathrm{x}+\mathrm{n}} \geq \mathrm{I}_{\mathrm{z}+\mathrm{n}}(1+\rho)^{\mathrm{x}}$ for all $\mathrm{x}$ in $\{1, \ldots, \mathrm{y}-1\}$. So with the decreasing investment demand function $\mathrm{R}$, we get

$$
\begin{aligned}
\sum_{x \in\{0, \ldots, y-1\}} R\left(I_{z}(1+\rho)^{x}\right) \leq \sum_{x \in\{0, \ldots, y-1\}} R\left(I_{z+x}\right)=r_{z+1}+\ldots+r_{z+y} \\
\quad=r_{z+1+n}+\ldots+r_{z+y+n}=\sum_{x \in\{0, \ldots, y-1\}} R\left(I_{z+x+n}\right) \leq \sum_{x \in\{0, \ldots, y-1\}} R\left(I_{z+n}(1+\rho)^{x}\right) .
\end{aligned}
$$

Together these imply $I_{z} \geq I_{z+n}$ and so $r_{z+1}=R\left(I_{z}\right) \leq R\left(I_{z+n}\right)=r_{z+1+n}$. But this inequality contradicts our original assumption that $\mathrm{r}_{\mathrm{z}+1}+\mathrm{r}_{\mathrm{z}+2}+\ldots+\mathrm{r}_{\mathrm{z}+\mathrm{n}}=\mathrm{M}>\mathrm{r}_{\mathrm{z}+2}+\ldots+\mathrm{r}_{\mathrm{z}+\mathrm{n}}+\mathrm{r}_{\mathrm{z}+1+\mathrm{n}}$.

Proof of Fact 6. The cohort decomposition equation [3] implies

$$
(1+\rho) I_{t}-I_{t+1}=(1+\rho)^{n} J_{t+1-n}-J_{t+1} .
$$

So if the difference $(1+\rho) I_{t}-I_{t+1}$ were strictly negative, we would get $J_{t+1}>(1+\rho)^{n} J_{t+1-n}$. But with cyclical $I_{t},(1+\rho) I_{t+n}-I_{t+n-1}$ would be equally negative, implying $J_{t+n+1}>(1+\rho)^{n} J_{t+1}$. Applying the same point every $n$ periods, we would get $J_{t+1+k n}>(1+\rho)^{k n} J_{t}$ for every positive integer $\mathrm{k}$. But in equilibrium, investors could not rationally hire new bankers to invest such unbounded amounts, which would drive surplus rates to zero. Thus, the cyclical equilibrium investments must satisfy $\mathrm{I}_{\mathrm{t}+1} \leq(1+\rho) \mathrm{I}_{\mathrm{t}}$ at every $\mathrm{t}$. With this constraint, cyclical values of $\left(\mathrm{J}_{0}, \ldots, \mathrm{J}_{\mathrm{n}-1}\right)$ that satisfy equation [3] with $\mathrm{J}_{\mathrm{t}+1}=\mathrm{J}_{\mathrm{t}+1-\mathrm{n}}$ for all $\mathrm{t} \geq 0$ can be found by applying

$$
(1+\rho) \mathrm{I}_{\mathrm{t}}-\mathrm{I}_{\mathrm{t}+1}=(1+\rho)^{\mathrm{n}} \mathrm{J}_{\mathrm{t}+1-\mathrm{n}}-\mathrm{J}_{\mathrm{t}+1}=\left[(1+\rho)^{\mathrm{n}}-1\right] \mathrm{J}_{\mathrm{t}+1},
$$

which yields equation [8] for computing $\mathrm{J}_{\mathrm{t}+1}$ from $\mathrm{I}_{\mathrm{t}}$ and $\mathrm{I}_{\mathrm{t}+1}$.

Proof of Fact 7. When an equilibrium credit cycle begins at time T, the $\mathrm{n}-1$ past periods' new-banker investment levels $\left(\mathrm{J}_{\mathrm{T}-1}, \ldots, \mathrm{J}_{\mathrm{T}-(\mathrm{n}-1)}\right)$ are taken as given. At each time $\mathrm{t}>\mathrm{T}$, the retiring bankers will be replaced by a new cohort with responsibilities $J_{t}=J_{t-n}$. So the only unknown in the credit cycle is $\mathrm{J}_{\mathrm{T}}$. But for $\mathrm{J}_{\mathrm{T}}$ to be positive, we must have

$$
\sum_{\mathrm{t} \in\{\mathrm{T}, \ldots, \mathrm{T}+\mathrm{n}-1\}} \mathrm{R}\left(\sum_{\mathrm{s} \in\{0, \ldots, \mathrm{n}-1\}} \mathrm{J}_{\mathrm{t}-\mathrm{s}}(1+\rho)^{\mathrm{s}}\right)=\mathrm{M} .
$$

The left-hand side of [12] is a decreasing continuous function of the unknown $\mathrm{J}_{\mathrm{T}}$, and it goes to 0 as $\mathbf{J}_{T}$ becomes very large. So either there exists some $\mathbf{J}_{T} \geq 0$ which satisfies equation [12] and starts the credit cycle, or else the left-hand side of [12] would be less than $\mathrm{M}$ even with $\mathrm{J}_{\mathrm{T}}=0$.

So to find a dynamic equilibrium that starts at time 0 with initial conditions $\left(\mathrm{J}_{-1}, \ldots, \mathrm{J}_{-(\mathrm{n}-1)}\right)$, we first consider equation [12] for $\mathrm{T}=0$. If this equation can be satisfied by some nonnegative $\mathrm{J}_{0} \geq 0$, then the credit cycle begins at time 0 with this $\mathrm{J}_{0}$. Otherwise, we let $\mathrm{J}_{0}=0$ and consider 
whether equation [12] can be satisfied at $\mathrm{T}=1$ with initial conditions $\left(\mathrm{J}_{0}, \mathrm{~J}_{-1}, \ldots, \mathrm{J}_{-(\mathrm{n}-2)}\right)$. If that cannot be done then we continue, setting the current unknown $\mathrm{J}$ to zero, increasing $\mathrm{T}$ by one, and reconsidering the problem of satisfying equation [12] at this next period $\mathrm{T}$. If we do not find a solution to equation [12] for $\mathrm{T}<\mathrm{n}-1$, we must get a positive solution for $\mathrm{J}_{\mathrm{T}}$ at $\mathrm{T}=\mathrm{n}-1$, because then all past J's will be 0 , and so the left-hand side of [12] would be $n R(0)>M$ if $J_{T}$ were 0 .

By Fact 5, after the first $T$ where equation [12] is satisfied, the credit cycle can continue to satisfy the equilibrium conditions [3]-[5] at all $\mathrm{t}>\mathrm{T}$ with the recursive equations $\mathrm{J}_{\mathrm{t}+\mathrm{n}}=\mathrm{J}_{\mathrm{t}}$.

When the investment-demand function $R(\bullet)$ is strictly decreasing, this cyclical equilibrium is unique for these initial conditions, because there cannot exist any other equilibrium that does not satisfy $J_{t}=J_{t-n}$ at all $t>$ T. By Fact 5, $R\left(I_{t+n}\right)=r_{t+1+n}=r_{t+1}=R\left(I_{t}\right)$ for all $\mathrm{t} \geq \mathrm{T}$. So with $\mathrm{R}$ strictly decreasing, we must have $\mathrm{I}_{\mathrm{t}+\mathrm{n}}-\mathrm{I}_{\mathrm{t}}=0$, and so

$$
\sum_{\mathrm{s} \in\{0, \ldots, \mathrm{n}-1\}}\left(\mathrm{J}_{\mathrm{t}+\mathrm{n}-\mathrm{s}}-\mathrm{J}_{\mathrm{t}-\mathrm{s}}\right)(1+\rho)^{\mathrm{s}}=0 .
$$

These equations for $\mathrm{t}$ and $\mathrm{t}+1$ imply

$$
\left(\mathrm{J}_{\mathrm{t}+1}-\mathrm{J}_{\mathrm{t}+1-\mathrm{n}}\right)(1+\rho)^{\mathrm{n}}=-\sum_{\mathrm{s} \in\{0, \ldots, \mathrm{n}-2\}}\left(\mathrm{J}_{\mathrm{t}+\mathrm{n}-\mathrm{s}}-\mathrm{J}_{\mathrm{t}-\mathrm{s}}\right)(1+\rho)^{\mathrm{s}+1}=\left(\mathrm{J}_{\mathrm{t}+1+\mathrm{n}}-\mathrm{J}_{\mathrm{t}+1}\right), \quad \forall \mathrm{t} \geq \mathrm{T} .
$$

So if the differences $J_{t+1}-J_{t+1-n}$ were not zero for all $t \geq T$, then these differences would become unbounded as $t \rightarrow \infty$. But in an equilibrium, $J_{t}$ must be bounded between 0 and $R^{-1}(M / n)$.

Proof of Fact 9. We compute derivatives with respect to the tax rate $\tau$ at $\tau=0$. The quantities $\mathrm{J}_{\mathrm{t}}=\mathrm{J}_{\mathrm{t}-\mathrm{n}}$ for $\mathrm{t} \in\{2, \ldots, \mathrm{n}-1\}$ do not depend on $\tau$, and $\mathrm{J}_{\mathrm{n}}=\mathrm{J}_{0}$. With $\tau=0$, we get

$$
\mathrm{K}_{0}=\tau \mathrm{I}_{0} /\left(\mathrm{M}-\mathrm{r}_{1}\right)=0 \text { and } \mathrm{dK}_{0} / \mathrm{d} \tau=\mathrm{I}_{0} /\left(\mathrm{M}-\mathrm{r}_{1}\right) .
$$

Then from $M=r_{2}+\ldots+r_{n+1}$ and $r_{1}-\tau=r_{n+1}$, we get two equations for $d J_{0} / d \tau$ and $d J_{1} / d \tau$ :

$$
\begin{aligned}
& {\left[(1+\rho) \mathrm{dJ}_{0} / \mathrm{d} \tau+\mathrm{dJ} \mathrm{J}_{1} / \mathrm{d} \tau\right]\left[\sum_{\mathrm{s} \in\{1, \ldots, \mathrm{n}\}} \mathrm{R}^{\prime}\left(\mathrm{I}_{\mathrm{s}}\right)(1+\rho)^{\mathrm{s}-1}\right]+\mathrm{R}^{\prime}\left(\mathrm{I}_{\mathrm{n}}\right)\left[(1+\rho)^{\mathrm{n}-1} \mathrm{dJ_{1 }} / \mathrm{d} \tau+\mathrm{dJ_{0 }} / \mathrm{d} \tau\right]=0,} \\
& \mathrm{R}^{\prime}\left(\mathrm{I}_{0}+\mathrm{K}_{0}\right)\left[\mathrm{I}_{0} /\left(\mathrm{M}-\mathrm{r}_{1}\right)+\mathrm{d} \mathrm{J}_{0} / \mathrm{d} \tau\right]-1=\mathrm{R}^{\prime}\left(\mathrm{I}_{\mathrm{n}}\right)\left[(1+\rho)^{\mathrm{n}-1} \mathrm{dJ}_{1} / \mathrm{d} \tau+\mathrm{d} \mathrm{J}_{0} / \mathrm{d} \tau\right] .
\end{aligned}
$$

By linearity, the derivative is constant $\mathrm{R}^{\prime}=-\mathrm{b}$, and $\mathrm{I}_{0} /\left(\mathrm{M}-\mathrm{r}_{1}\right)=\mathrm{I}_{0} /(\mathrm{M}+\mathrm{bI}-\mathrm{A})$. So these equations simplify to

$$
-\mathrm{dJ}_{0} / \mathrm{d} \tau=\mathrm{dJ}_{1} / \mathrm{d} \tau=\left[\mathrm{I}_{0} /\left(\mathrm{M}+\mathrm{bI} \mathrm{I}_{0}-\mathrm{A}\right)+1 / \mathrm{b}\right] /(1+\rho)^{\mathrm{n}-1}
$$

So at $\tau=0$, the derivative of total time- 0 investment with respect to the tax rate $\tau$ is

$$
\begin{gathered}
\mathrm{d}\left(\mathrm{K}_{0}+\mathrm{I}_{0}\right) / \mathrm{d} \tau=\mathrm{dK}_{0} / \mathrm{d} \tau+\mathrm{dJ} \mathrm{J}_{0} / \mathrm{d} \tau=\mathrm{I}_{0} /\left(\mathrm{M}+\mathrm{bI}_{0}-\mathrm{A}\right)-\left[\mathrm{I}_{0} /\left(\mathrm{M}+\mathrm{bI} \mathrm{I}_{0}-\mathrm{A}\right)+1 / \mathrm{b}\right] /(1+\rho)^{\mathrm{n}-1} \\
=\left\{\mathrm{bI}_{0}\left[(1+\rho)^{\mathrm{n}-1}-2\right]+(\mathrm{A}-\mathrm{M})\right\} /\left[\mathrm{b}(1+\rho)^{\mathrm{n}-1}\left(\mathrm{M}-\mathrm{r}_{1}\right)\right]
\end{gathered}
$$

which is positive when $(1+\rho)^{\mathrm{n}-1}>2$ and $\mathrm{A}>\mathrm{M}$. 


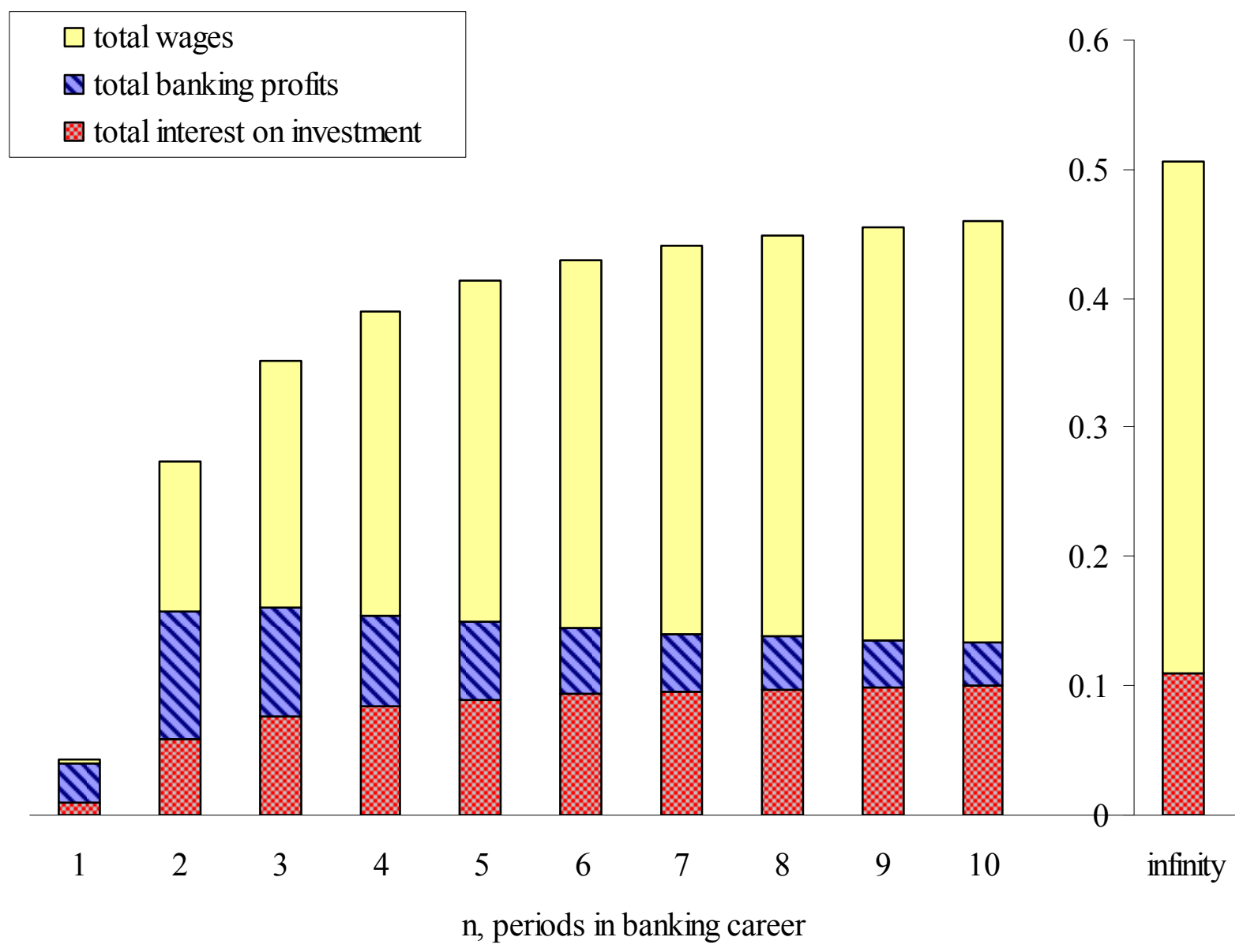

Figure 1. Output shares in steady state for various $n$, with $\rho=0.1, M=0.33, A=0.36, b=0.327$. 


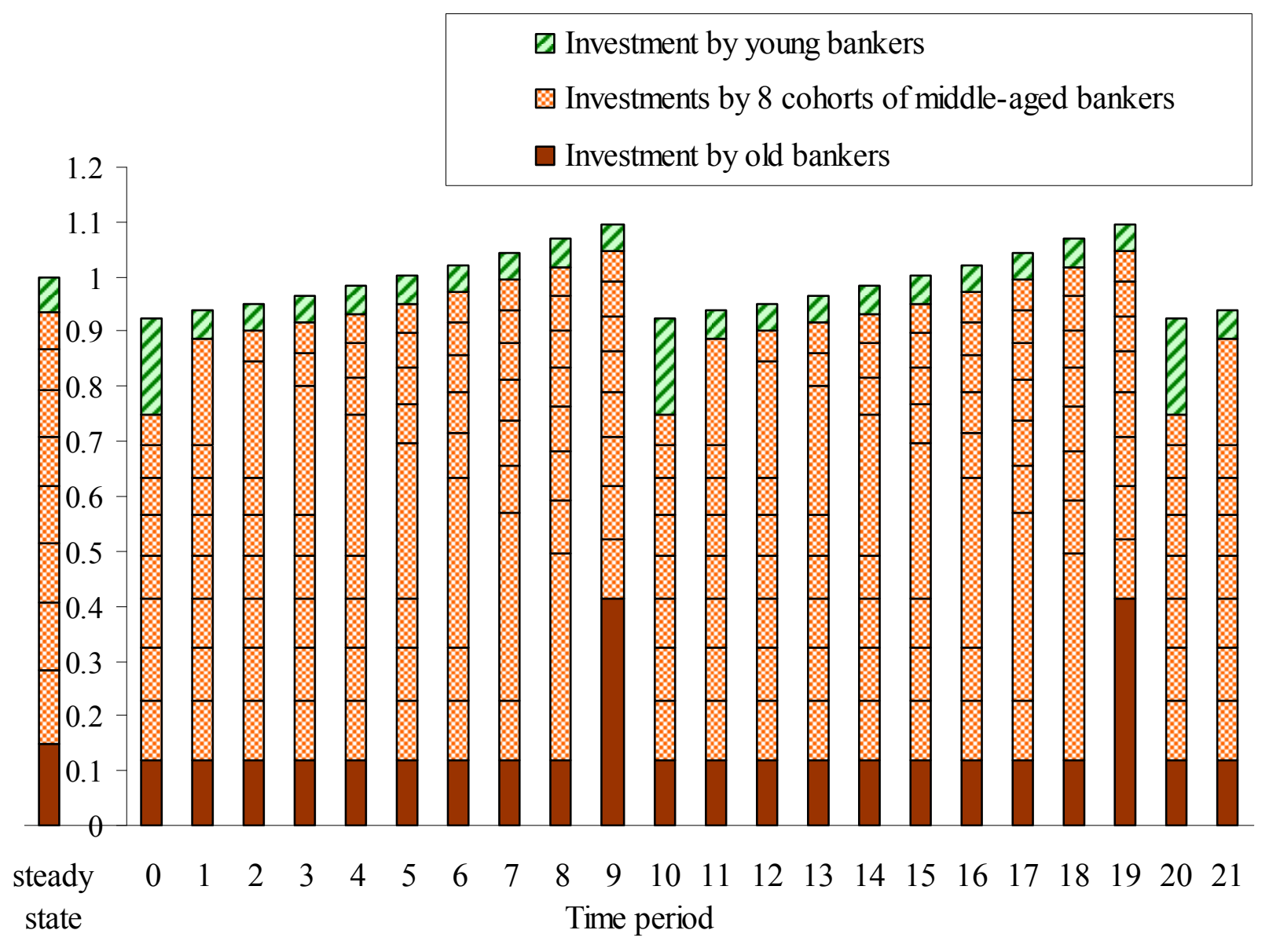

Figure 2. Investment amounts supervised by different cohorts of bankers in a dynamic equilibrium that starts with mid-career bankers' investments at time 0 being $80 \%$ of steady state. Parameters: $n=10, \rho=0.1, M=0.33, A=0.36, b=0.327$. 


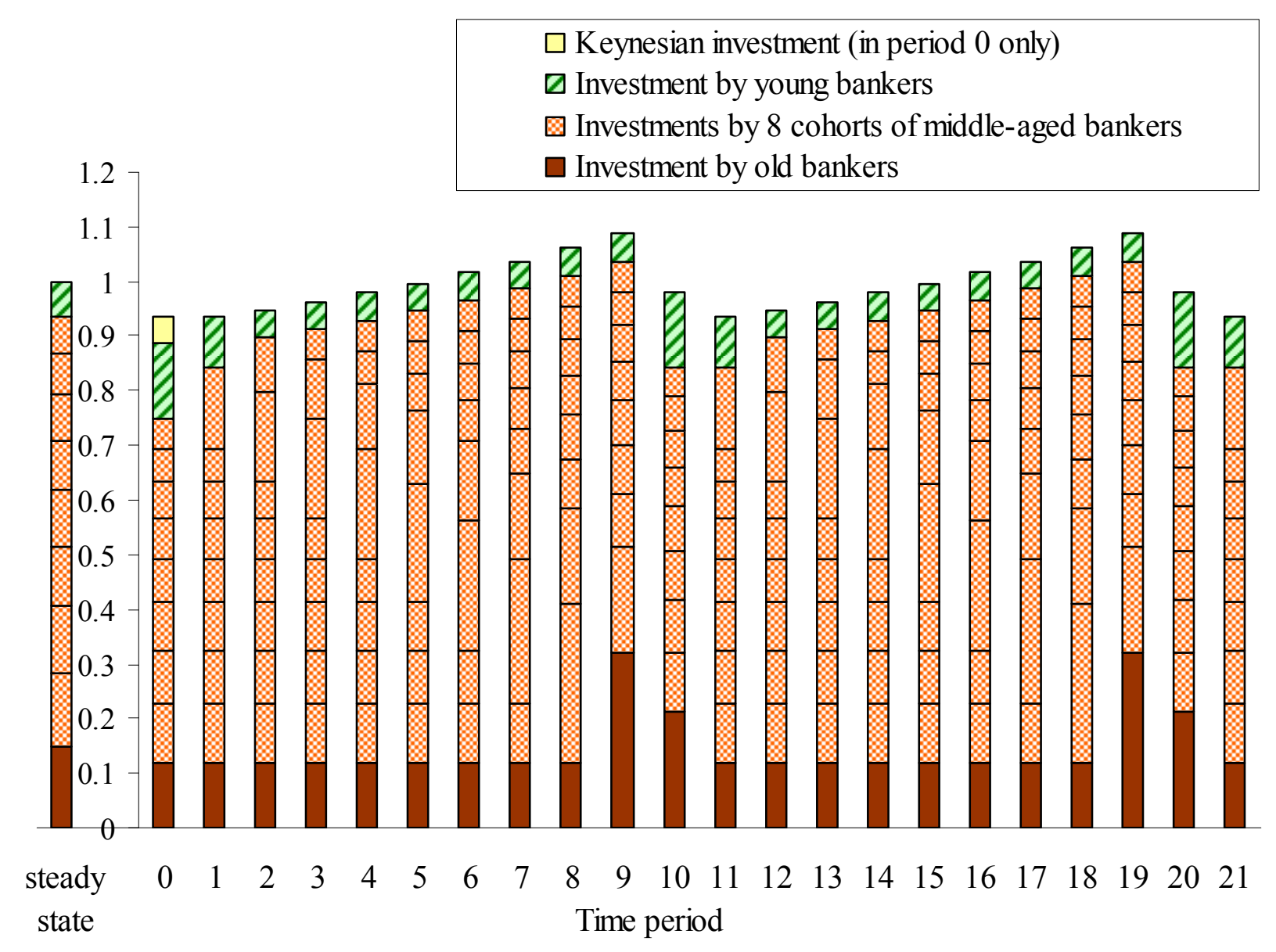

Figure 3. Investment amounts supervised by different cohorts of bankers in an equilibrium that starts with continuing bankers' investments at time 0 being $80 \%$ of steady state, but with a shortterm balanced fiscal stimulus at time 0 with tax rate $\tau=0.015$. Parameters as in Figure 2 . 


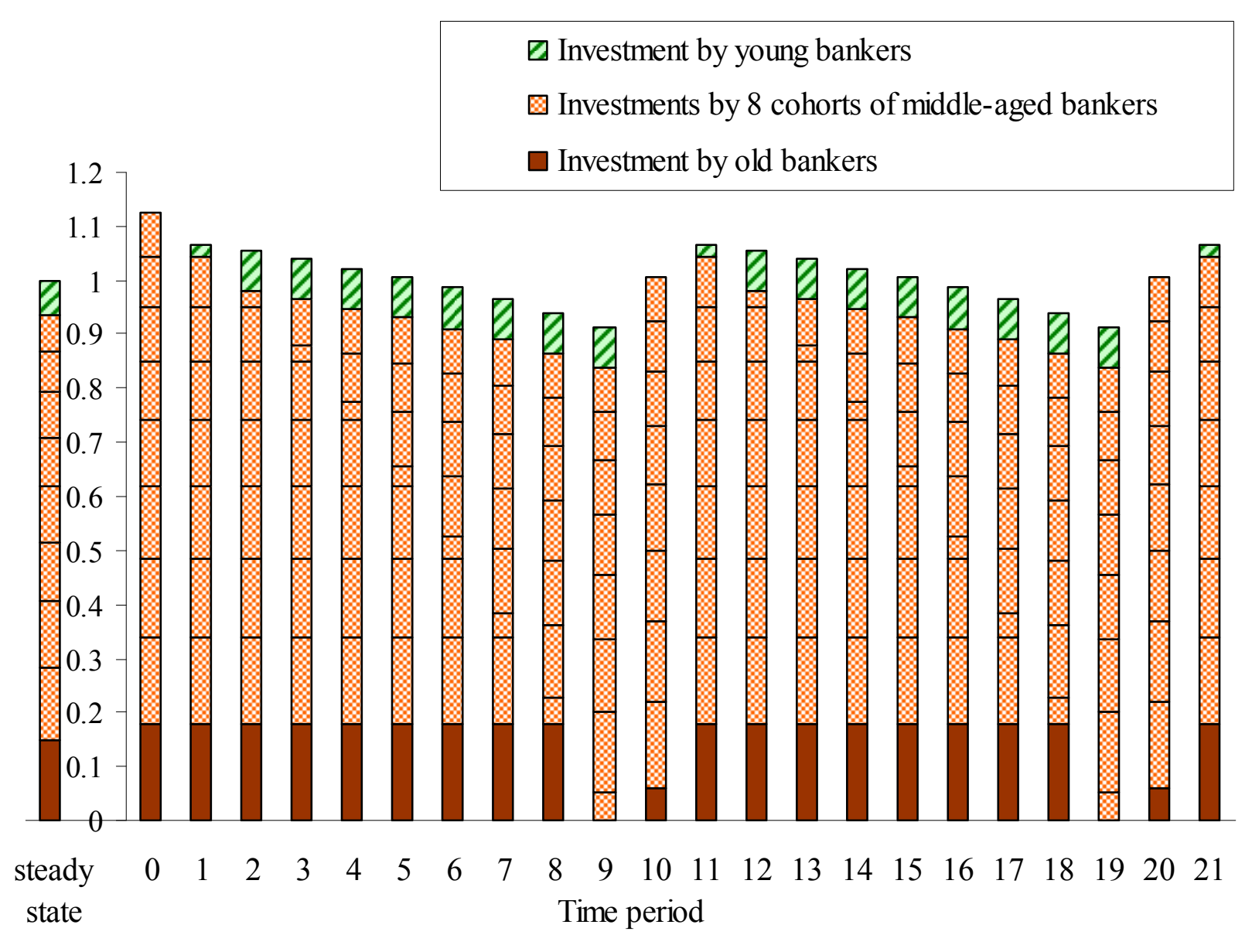

Figure 4. Investment amounts supervised by different cohorts of bankers in a dynamic equilibrium that starts with continuing bankers' investments at time 0 being $120 \%$ of steady state (zombie banks). Parameters as in Figure 2. 


\section{References}

Costas Azariadis and Bruce Smith, "Financial intermediation and regime switching in business cycles," American Economic Review 88(3):516-536 (1998).

Gary Becker and George Stigler, "Law enforcement, malfeasance, and compensation of enforcers," Journal of Legal Studies 3(1):1-18 (1974).

Ben Bernanke and Mark Gertler, "Agency costs, net worth, and business fluctuations," American Economic Review 79(1):14-31 (1989).

Bruno Biais, Thomas Mariotti, Jean-Charles Rochet, Stephane Villeneuve, "Large risks, limited liability, and dynamic moral hazard," Econometrica 78(1):73-118 (2010).

Markus K. Brunnermeier and Yuliy Sannikov, "A macroeconomic model with a financial sector," Princeton University working paper (2009).

Harold L. Cole, Jeremy Greenwood, and Juan M. Sanchez, "Why doesn't technology flow from rich to poor countries," SSRN working paper http://ssrn.com/abstract=1945981, (2011).

Douglas W. Diamond, "Financial intermediation and delegated monitoring," Review of Economic Studies 51(3):393-414 (1984).

Giovanni Favara, "Agency problems and endogenous investment fluctuations," Review of Financial Studies 25(7):2301-2342 (2012).

Nicholas Figueroa and Oksana Leukhina, "Business cycles and lending standards," University of Washington working paper (2010).

Xavier Freixas and Jean-Charles Rochet, Microeconomics of Banking, MIT Press (1997).

Chao Gu and Randall Wright, "Endogenous credit cycles," NBER working paper 17510 (2011).

Zhiguo He and Arvind Krishnamurthy, "A model of capital and crises," NBER working paper 14366 (2008), forthcoming in Review of Economic Studies.

Bengt Holmstrom and Jean Tirole, "Financial intermediation, loanable funds and the real sector," Quarterly Journal of Economics 112(3):663-691 (1997).

Alberto Martin, "Endogenous credit cycles," Universitat Pompeu Fabra working paper (2008).

Nobuhiro Kiyotaki and John Moore, "Credit cycles," Journal of Political Economy 105(2):211248 (1997).

Yunan Li and Cheng Wang, "Endogenous cycles in a model of the labor market with dynamic moral hazard," Tsinghua University working paper (2010).

Kiminori Matsuyama, "The good, the bad, and the ugly: an inquiry into the causes and nature of credit cycles," Northwestern University working paper (2012), forthcoming in 


\section{Theoretical Economics.}

Roger Myerson, "Moral-hazard credit cycles with risk-averse agents," working paper at http://home.uchicago.edu/ rmyerson/research/rabankers.pdf (2012).

Thomas Philippon, "The evolution of the US financial industry from 1860 to 2007: theory and evidence," NYU working paper (2008).

Pietro Reichlin and Paulo Siconolfi, "Optimal debt contracts and moral hazard along the business cycle," Economic Theory 24(1):75-109 (2004).

Carl Shapiro and Joseph E. Stiglitz, "Equilibrium unemployment as a worker disciplinary device," American Economic Review 74(3):433-444 (1984).

Javier Suarez and Oren Sussman, "Endogenous cycles in a Stiglitz-Weiss economy," Journal of Economic Theory 76(1):47-71 (1997).

Javier Suarez and Oren Sussman, "Financial distress, bankruptcy law and the business cycle," Annals of Finance 3(1):5-35 (2007).

Jean Tirole, The Theory of Corporate Finance, Princeton University Press (2006).

AUTHOR'S ADDRESS:

Roger Myerson, Economics Department, University of Chicago, 1126 East 59th Street, Chicago, IL 60637.

Phone: 1-773-834-9071. Fax: 1-773-702-8490. Email: myerson@uchicago.edu

Web site: http://home.uchicago.edu/ rmyerson/

This paper: http://home.uchicago.edu/ rmyerson/research/bankers.pdf

[current version: Sept 18, 2012] 